\title{
Argonne
}

\section{Idling Reduction for Long-Haul Trucks: An Economic Comparison of On-Board and Wayside Technologies}

Energy Systems Division

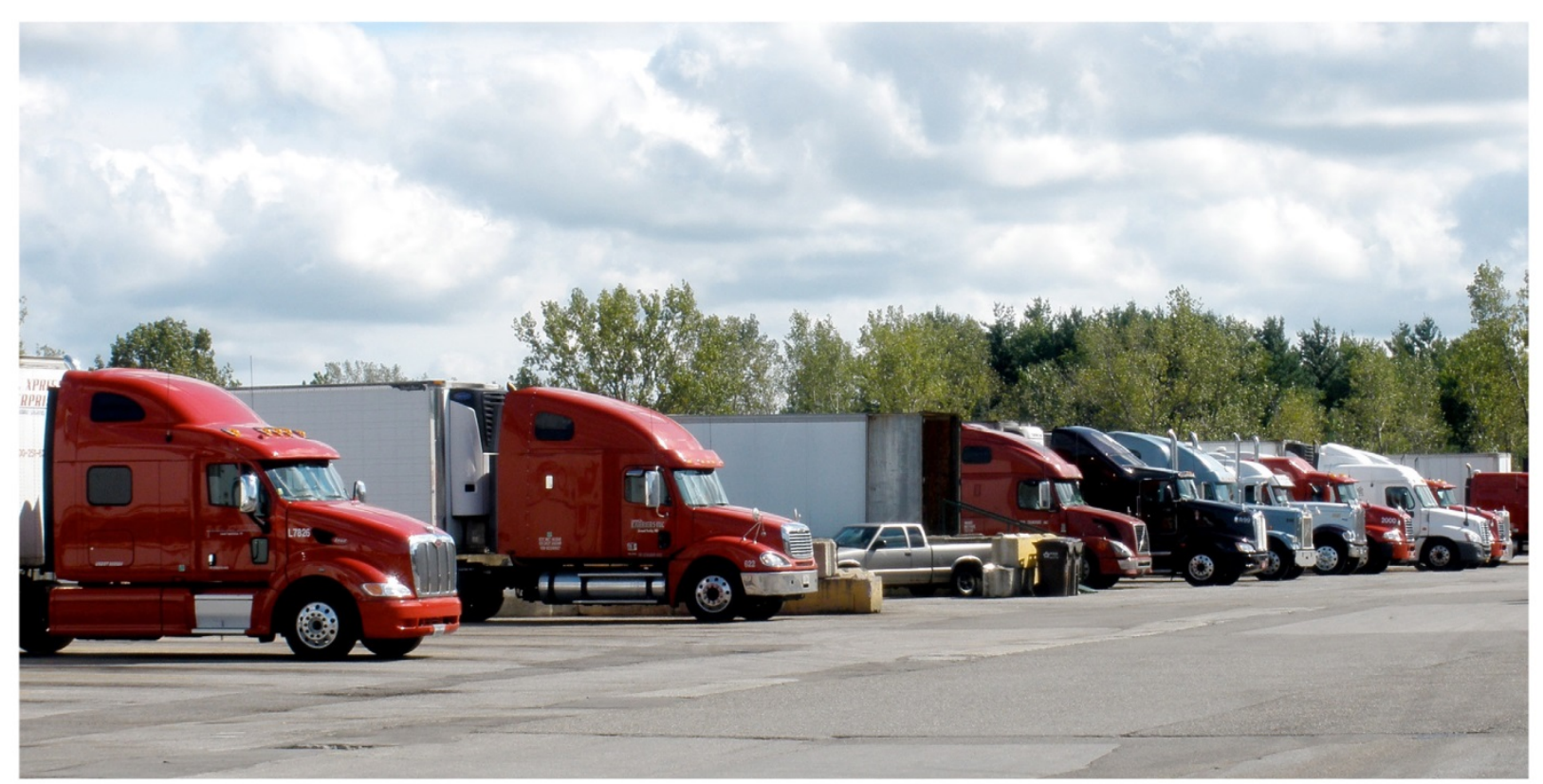




\title{
COVER PHOTO
}

Patricia Weikersheimer

\section{ACKNOWLEDGMENTS}

The authors would like to thank the U.S. DOE Clean Cities program for its support; Terry Levinson of Allegheny Science \& Technology for her review of the paper; and IdleAir and Shorepower Technologies for sharing their data.

\author{
About Argonne National Laboratory \\ Argonne is a U.S. Department of Energy laboratory managed by UChicago Argonne, LLC \\ under contract DE-AC02-06CH11357. The Laboratory's main facility is outside Chicago, \\ at 9700 South Cass Avenue, Argonne, Illinois 60439. For information about Argonne \\ and its pioneering science and technology programs, see www.anl.gov.
}

\section{DOCUMENT AVAILABILITY}

Online Access: U.S. Department of Energy (DOE) reports produced after 1991 and a growing number of pre-1991 documents are available free via DOE's SciTech Connect (http://www.osti.gov/scitech/).

Reports not in digital format may be purchased by the public from the National Technical Information Service (NTIS):

U.S. Department of Commerce

National Technical Information Service

5301 Shawnee Rd

Alexandria, VA 22312

www.ntis.gov

Phone: (800) 553-NTIS (6847) or (703) 605-6000

Fax: (703) 605-6900

Email: orders@ntis.gov

Reports not in digital format are available to DOE and DOE contractors from the Office of Scientific and Technical Information (OSTI):

U.S. Department of Energy

Office of Scientific and Technical Information

P.O. Box 62

Oak Ridge, TN 37831-0062

www.osti.gov

Phone: (865) 576-8401

Fax: (865) 576-5728

Email: reports@osti.gov

\footnotetext{
Disclaimer

This report was prepared as an account of work sponsored by an agency of the United States Government. Neither the United States Government nor any agency thereof, nor UChicago Argonne, LLC, nor any of their employees or officers, makes any warranty, express or implied, or assumes any legal liability or responsibility for the accuracy, completeness, or usefulness of any information, apparatus, product, or process disclosed, or represents that its use would not infringe privately owned rights. Reference herein to any specific commercial product, process, or service by trade name, trademark, manufacturer, or otherwise, does not necessarily constitute or imply its endorsement, recommendation, or favoring by the United States Government or any agency thereof. The views and opinions of document authors expressed herein do not necessarily state or reflect those of the United States Covernment or any agency thereof, Argonne National Laboratory, or UChicago Argonne, LLC.
} 


\section{Idling Reduction for Long-Haul Trucks: An Economic Comparison of On-Board and Wayside Technologies}

by

Linda Gaines ${ }^{1}$ and Patricia Weikersheimer ${ }^{2}$

${ }^{1}$ Energy Systems Division, Argonne National Laboratory

${ }^{2}$ Communications, Education, and Public Affairs Division, Argonne National Laboratory

September 2016 



\section{CONTENTS}

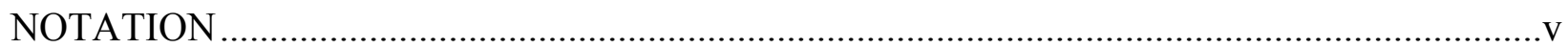

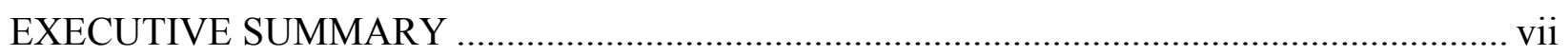

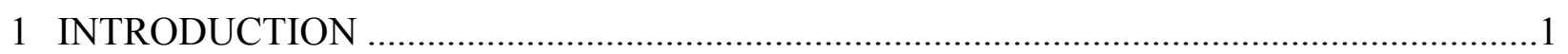

2 IDLING REDUCTION EQUIPMENT AND CONSIDERATIONS ....................................

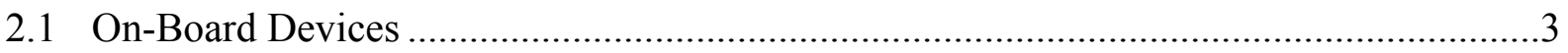

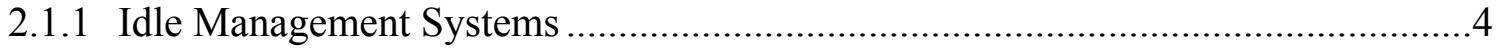

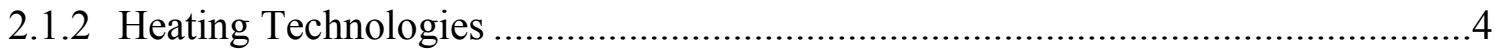

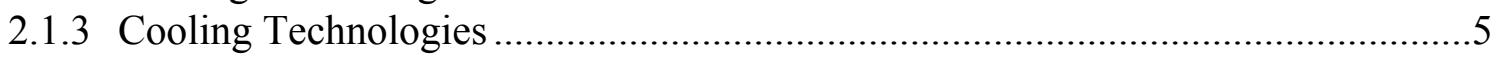

2.1.4 Auxiliary Power Units .............................................................................6

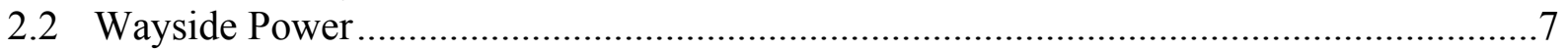

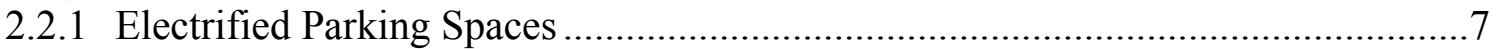

2.2.1.1 Single-System Electrification.....................................................

2.2.1.2 Dual-System Electrification .......................................................

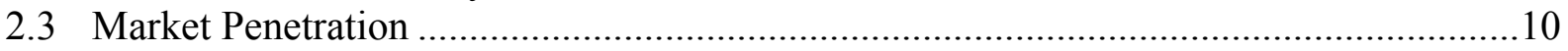

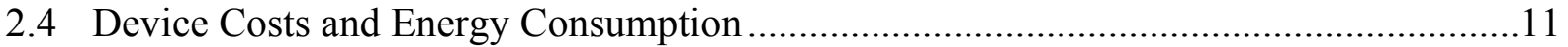

3 TOTAL COSTS AND PAYBACK FOR THE TRUCK OWNER ..........................................13

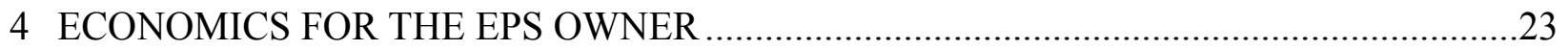

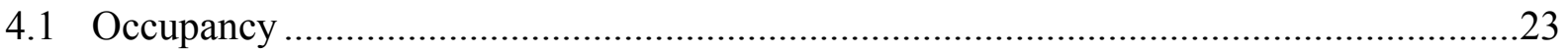

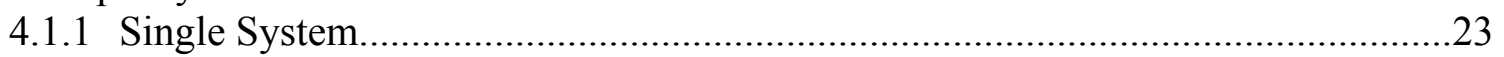

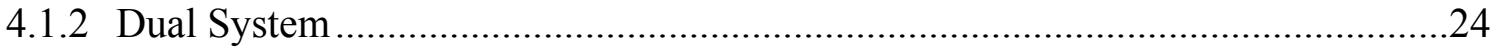

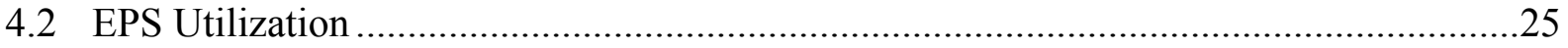

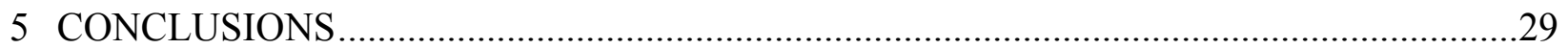

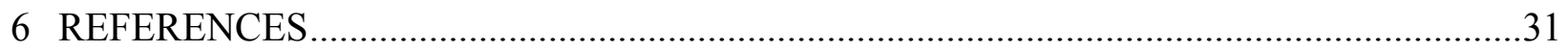

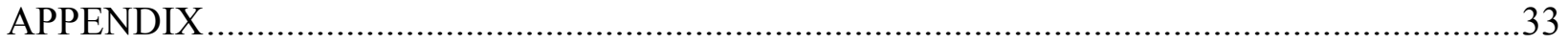

\section{FIGURES}

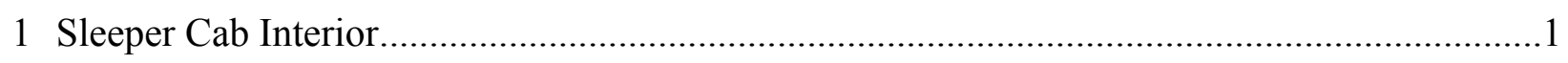

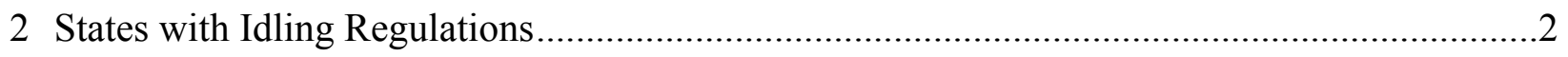

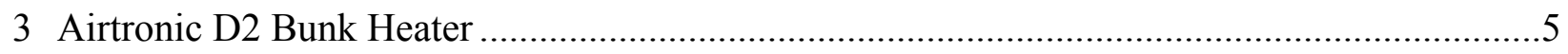

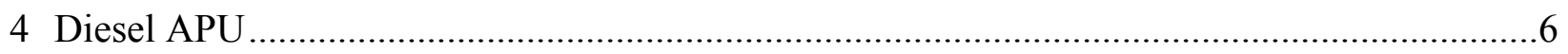

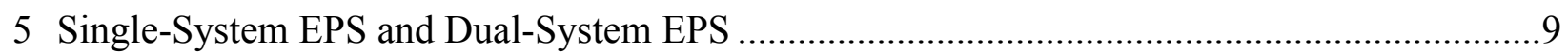

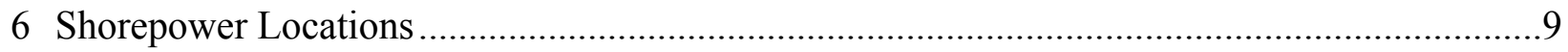

7 NACFE Fleets Adoption of IR Technologies ............................................................. 10

8 On-Board IR Equipment Capital Costs ......................................................................... 14 


\section{FIGURES (CONT.)}

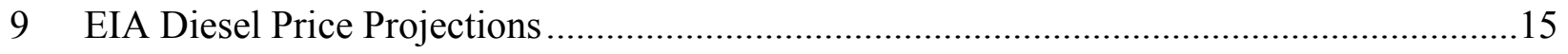

10 Operating Costs for IR Equipment, as a Function of Fuel Price........................................15

11 Total Cost over 5 Years as a Function of Fuel Price for Low Idlers...................................16

12 Total Cost over 5 Years as a Function of Fuel Price for High Idlers .................................16

13 Total Cost over 5 Years as a Function of Idling Hours for Low Fuel Price ........................17

14 Total Cost over 5 Years as a Function of Idling Hours for High Fuel Price.........................18

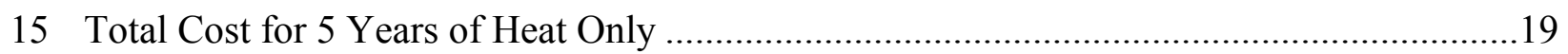

16 Annual Operating Costs as Equipment Is Paid Off, High Idlers at High Fuel Price.............19

17 Annual Operating Costs as Equipment Is Paid Off, Low Idlers at Low Fuel Price ..............20

18 Equipment Payback Time as a Function of Fuel Price, High Idlers .................................21

19 Equipment Payback Time as a Function of Fuel Price, Low Idlers ...................................21

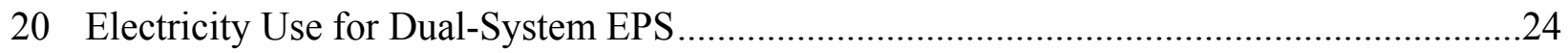

21 Variation of Dual-System Energy Use by Day of the Week...............................................25

22 Variation of Dual-System EPS Occupancy Energy Use by Time of Day..........................25

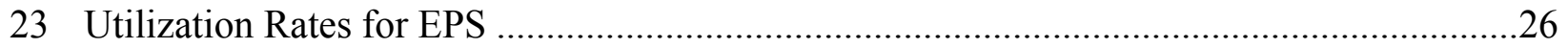

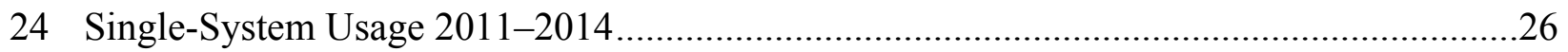

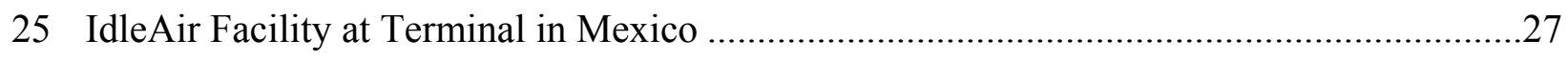

\section{TABLES}

1 Cab Comfort Options for Heavy-Duty Trucks: Fuel Use, Costs, and Typical Payback ........11

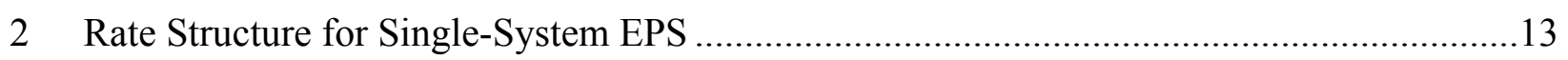




\section{NOTATION}

\begin{tabular}{|c|c|}
\hline $\mathrm{AC}$ & air-conditioning \\
\hline APU & auxiliary power unit \\
\hline Argonne & Argonne National Laboratory \\
\hline ARRA & American Recovery and Reinvestment Act of 2009 \\
\hline ATRI & American Transportation Research Institute \\
\hline $\begin{array}{l}\text { CARB } \\
\mathrm{CO}_{2}\end{array}$ & $\begin{array}{l}\text { California Air Resources Board } \\
\text { carbon dioxide }\end{array}$ \\
\hline DOE & U.S. Department of Energy \\
\hline EIA & Energy Information Administration \\
\hline EPA & U.S. Environmental Protection Agency \\
\hline EPS & electrified parking space \\
\hline${ }^{\circ} \mathrm{F}$ & degree(s) Fahrenheit \\
\hline FMCSA & Federal Motor Carrier Safety Administration \\
\hline g & $\operatorname{gram}(\mathrm{s})$ \\
\hline gal & gallon(s) \\
\hline $\mathrm{h}$ & $\operatorname{hour}(\mathrm{s})$ \\
\hline HVAC & heating, ventilation, and air-conditioning \\
\hline IR & idling reduction \\
\hline $\mathrm{kWh}$ & kilowatt-hour(s) \\
\hline $\mathrm{lb}$ & pound(s) \\
\hline mo & $\operatorname{month}(\mathrm{s})$ \\
\hline mpg & mile(s) per gallon \\
\hline NACFE & North American Council for Freight Efficiency \\
\hline NHTSA & National Highway Traffic Safety Administration \\
\hline NOx & oxides of nitrogen \\
\hline OEM & original equipment manufacturer \\
\hline PM & particulate matter \\
\hline
\end{tabular}




$\begin{array}{ll}\begin{array}{l}\text { ROI } \\ \text { RP } \\ \text { RPM }\end{array} & \begin{array}{l}\text { return on investment } \\ \text { Recommended Practice } \\ \text { revolutions per minute }\end{array} \\ \text { STEP } & \text { Shorepower Truck-Stop Electrification Program } \\ \text { TMC } & \begin{array}{l}\text { Technology and Maintenance Council } \\ \text { truck stop electrification }\end{array} \\ \text { USCB } & \text { U.S. Bureau of the Census } \\ \text { V } & \text { volt(s) } \\ \text { VIUS } & \text { Vehicle Inventory and Use Survey } \\ \text { yr } & \text { year(s) }\end{array}$




\section{EXECUTIVE SUMMARY}

Reducing the idling of long-haul heavy-duty trucks has long been recognized as a particularly low-hanging fruit of fuel efficiency and emissions reduction. The displacement of about 10 hours of diesel idling every day, for most days of the year, for as many as a million long-haul trucks has very clear benefits.

This report considers the costs and return on investment (ROI) for idling reduction (IR) equipment for both truck owners and electrified parking space (EPS) equipment owners. For the truck owners, the key variables examined are idling hours to be displaced (generally 1,000 to $2,000$ hours per year) and the price of fuel ( $\$ 0$ to $\$ 5 / \mathrm{gal})$. The ideal IR option would provide complete services in varied climates in any location and offer the best ROI on trucks that log many idling hours. For trucks that have fewer idling hours, options with a fixed cost per hour (i.e., EPS) might be most attractive if they were available to all, or even most, truck drivers. EPS, however, is particularly cost effective for trucks on prescribed routes with a need for regular, extended stops at terminals. (EPS is also called truck stop electrification, or TSE.)

The analysis shows that all IR options save money when fuel costs more than $\$ 2 /$ gal. For trucks requiring bunk heat, a simple heater (plug-in or diesel) is almost always the most costeffective way to provide heat, even if the truck is equipped with an auxiliary power unit (APU) or is parked at a single-system EPS location. For trucks requiring bunk air-conditioning, the use of single-system EPS is most cost effective for those logging fewer idling hours. Even for trucks with higher idling hours, the cost of EPS may be about the same as that for on-board air-conditioning. Clearly, trucks' locations and seasonal factors - and the availability of EPSare significant in the choice of "best fit" IR equipment for truck owners.

This report also considers costs and payback for owners of EPS infrastructure. An industry that 5 years ago had at least five players has been narrowed to two companies - one in single-system EPS (IdleAir) and the other in dual-system EPS (Shorepower Technologies). Use of EPS by truck drivers has not met initial expectations for a variety of reasons. One area where EPS has particular promise, however, is in the cost-effective provision of reliable air-conditioning.

This analysis is focused strictly on cost and fuel savings; it does not consider the important benefits of reduced emissions (i.e., greenhouse gases and criteria pollutants). It is important to note that all IR options provide some emissions benefits. Even where an IR option may not have a rapid ROI, the emissions-reduction benefit may be considerable. Finally, as the U.S. Environmental Protection Agency (EPA) and the U.S. Department of Transportation's National Highway Traffic Safety Administration (NHTSA) set stricter standards to reduce greenhouse gas emissions and improve the fuel efficiency of medium- and heavy-duty vehicles, the emissions benefits of IR strategies will become increasingly important. 
This page left intentionally blank. 


\section{INTRODUCTION}

Many long-haul trucks still idle overnight to provide "hotel load"heating, cooling, and electricity-for drivers taking their federally mandated rest periods in sleeper cabs (see Figure 1). Argonne National Laboratory (Argonne) estimates that rest-period idling of longhaul sleeper trucks consumes up to 1 billion gallons of fuel annually at a cost of around $\$ 3$ billion. The associated emissions consequences for carbon dioxide $\left(\mathrm{CO}_{2}\right)$ alone are 10 million tons annually. Additional idling occurs during the workday at places like loading docks and border crossings, where trucks must often wait for extended periods in queues.

The Federal Motor Carrier Safety Administration's (FMCSA's) Hours of Service (HOS) rule regulates the minimum number of hours long-haul drivers must rest. A driver may drive a maximum of 11 hours after 10 consecutive hours off duty and may not drive after 14 consecutive hours on duty. After a work week of 60 hours in 7 days or 70 hours in 8 days, the driver must have 34 consecutive hours off duty before restarting (FMSCA 2014). Recent data on the number of sleeper trucks traveling far enough daily to require an operator rest

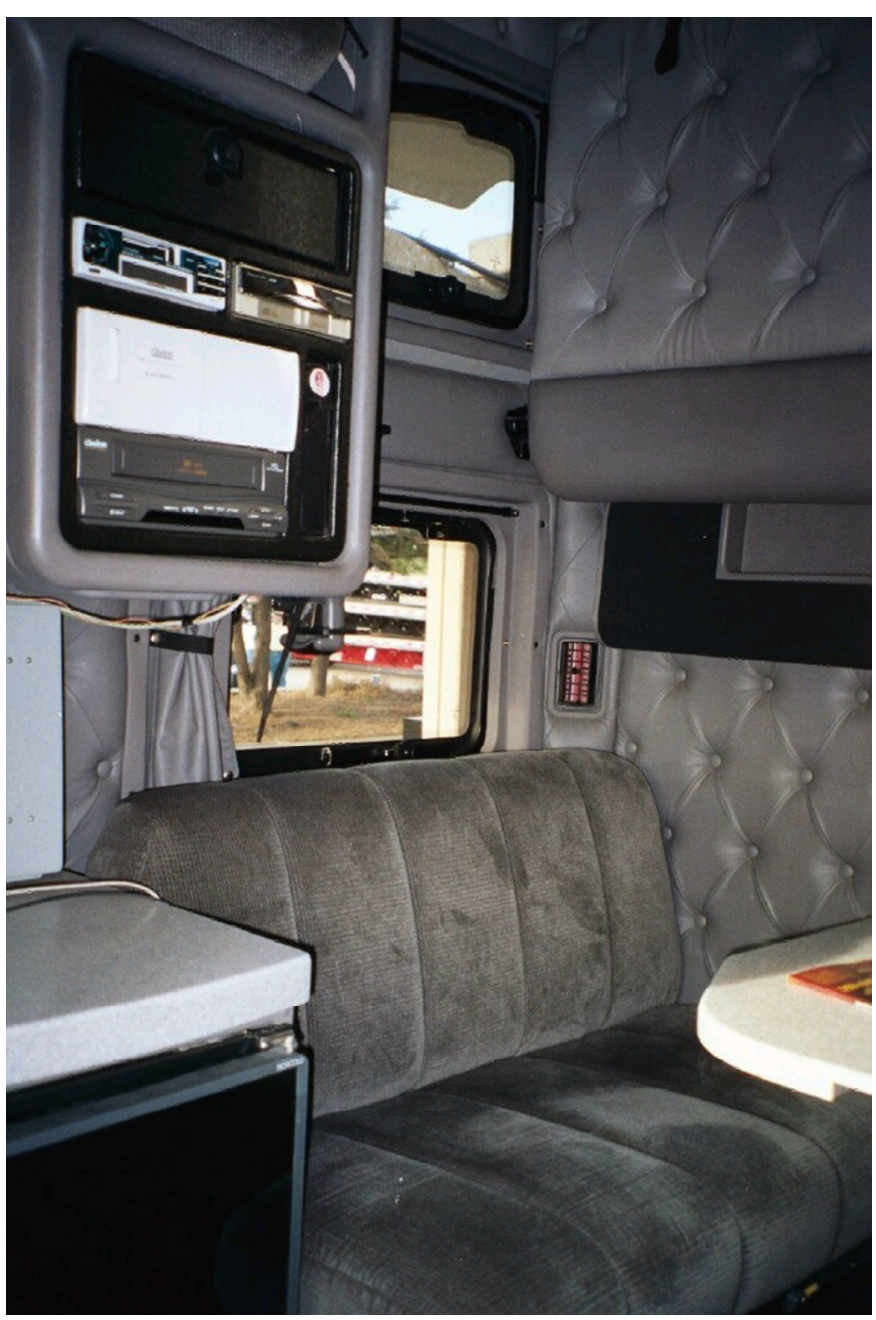

FIGURE 1 Sleeper Cab Interior (Photo: Linda Gaines) period are hard to obtain. In 2006, Argonne (Gaines et al. 2006) estimated 660,000 trucks based on the U.S. Census Bureau's Vehicle Inventory and Use Survey (VIUS) (USCB 2002), last performed in 2002. In the absence of new sleeper-truck data, Argonne estimates that there are now about 1 million sleeper trucks whose drivers rest overnight in the cab.

While no federal law addresses idling, numerous states and jurisdictions regulate the idling of heavy-duty diesel vehicles. This means that long-haul carriers have to track and comply with a patchwork of laws (see Figure 2). IdleBase (http://cleancities.energy.gov/idlebase), developed by Argonne for the U.S. Department of Energy (DOE) Clean Cities Program, provides complete information about regulations for all classes of on-road vehicles, and the American Transportation Research Institute (ATRI) produces a list and cab card of regulations and penalties specific to heavy-duty trucks to help its members keep up to date and avoid potentially 
hefty fines (ATRI 2016). Complicating the picture is the spotty enforcement of these laws; thus the effect of those regulations is uneven.

In California, for example, idling of heavy-duty diesel trucks and buses is restricted to 5 minutes. Fines start at $\$ 300$ and rise to $\$ 1,000$ per day (CARB 2013). However, California permits the idling of trucks that meet the low oxides of nitrogen (NOx) idling emission standard $(\leq 30 \mathrm{~g} / \mathrm{h})$ and are parked more than 100 feet from any residential area. (These trucks must display the CARB "Clean Idle" sticker. That these stickers can be purchased for a few dollars on eBay is concerning.) Although "Clean Idle" trucks have low NOx emissions, they still burn fuel and emit $\mathrm{CO}_{2}$ when idling.

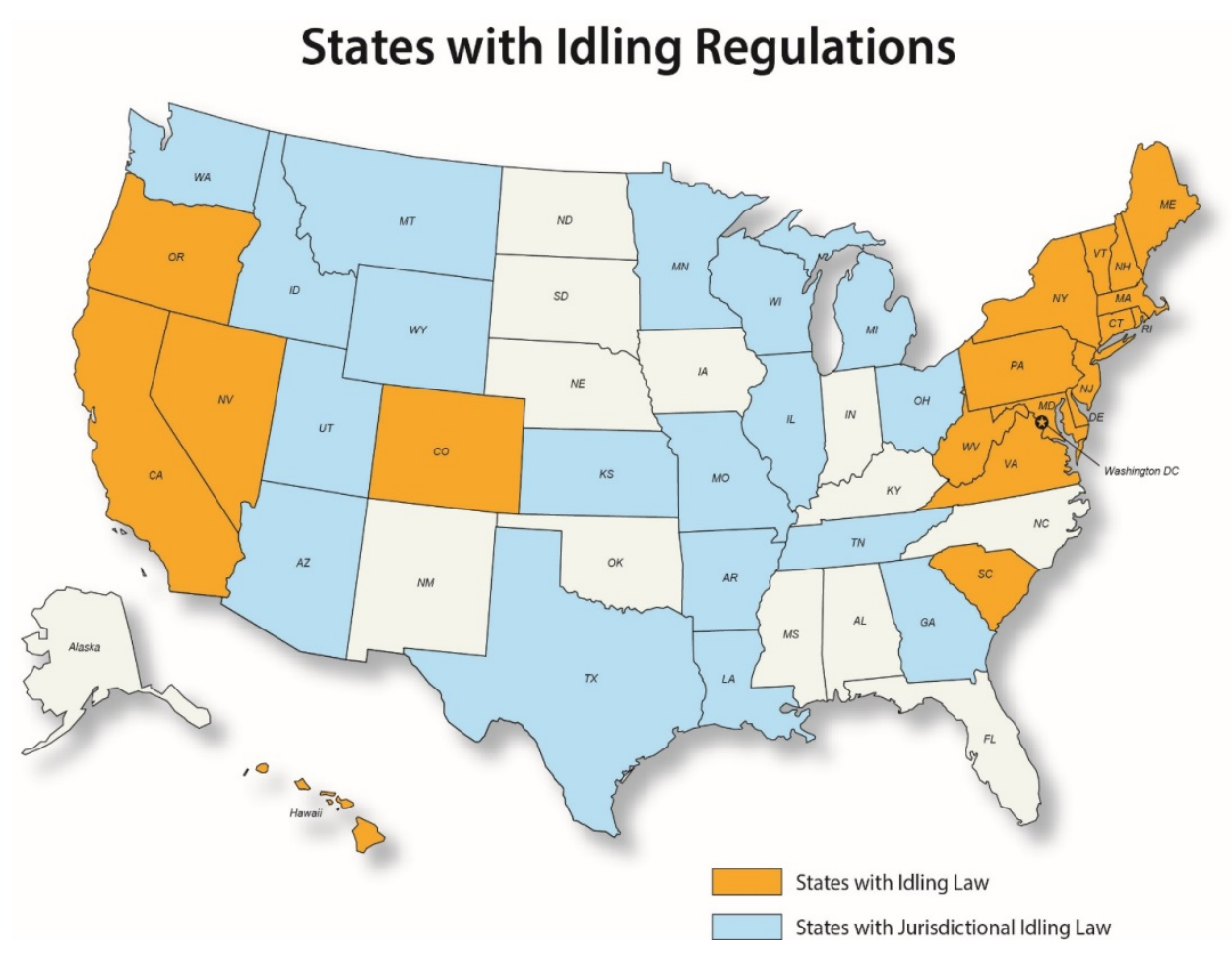

FIGURE 2 States with Idling Regulations 


\section{IDLING REDUCTION EQUIPMENT AND CONSIDERATIONS}

Systems that enable truck drivers to stay comfortable in their sleepers without idling their engines range from the basic - simply turning the engine off when power is not needed - to options that provide a full range of services, including cab and engine block heating, air-conditioning, lighting, and power for appliances and electronics. (One electrified parking space [EPS] service offers Internet access and cable TV.) Devices are available for stand-alone installation on board the truck ${ }^{1}$ or to plug into wayside-power installations, or both.

Idling reduction (IR) systems fall into two general categories: on-board and off-board, or wayside. On-board systems can be used anywhere the truck is parked; off-board systems require the truck driver to be parked at an equipped location. Some on-board systems have a plug-in option and straddle these categories. Because off-board systems are available in a limited set of locations, they may not be an option for many trucks.

The most cost-effective solution for any truck or fleet depends on where, how long, and what services are required during the driver's rest period. Each solution has advantages and disadvantages that must be weighed when choosing among them. Technologies that are cost effective for reducing overnight idling may be less attractive for workday idling because the fewer hours trucks idle per day while working is likely to result in a longer payback period. Further, for those vehicles that idle in queues (creep mode), some technology development may be required to enable slow vehicle motion without the use of the main engine. One possibility is the use of an auxiliary power unit (APU) to supply minimal motive power.

The U.S. Environmental Protection Agency's (EPA's) SmartWay Program recognizes, and verifies, IR equipment (EPA 2016). Many of the technologies were developed by industry in collaboration with the DOE; their recognition by the EPA is an example of the synergies among federal agencies.

\subsection{ON-BOARD DEVICES}

On-board devices have the advantage of being available wherever and whenever the truck is stopped. They have the disadvantage of cost and sometimes weight. The Energy Policy Act of 2005 includes a weight waiver, so the additional weight, up to $400 \mathrm{lb}$, does not decrease the revenue-producing load that can be carried. However, the Federal Highway Administration determined that individual states are not compelled to grant the increased weight tolerance (Ladage 2006). In 2012, when Moving Ahead for Progress in the 21st Century (MAP-21) was signed into law, the weight exemption was increased to $550 \mathrm{lb}$. States that recognize the weight exemption do so either by law or enforcement policy.

Some of these devices are available as factory-installed options on new trucks; all could be installed on new trucks or retrofitted on operating trucks. All are suitable to reduce overnight

1 The word "truck" refers to the tractor unit of a tractor semi-trailer combination, or to a single-unit truck. 
or workday idling (e.g., shorter breaks and waiting in queue), except as noted. However, the more costly alternatives will be shown to have long payback times for workday idling.

\subsubsection{Idle (or Power) Management Systems}

Idle management systems, or power management systems, turn the engine on and off as necessary to maintain cabin or sleeper-cab temperature and sufficient battery charge. These systems do not eliminate idling but reduce it, along with associated fuel use, engine wear, and emissions. (An automatic engine idle limiter, also called an idle shutdown timer, is an inexpensive control that simply shuts the engine off when the truck is stationary for more than a set period of time, typically 5 minutes. Although these devices are widely available, they do not support cab comfort and will not be discussed here. ${ }^{2}$ )

The automatic start-stop system monitors the cabin or sleeper temperature and/or the condition of the engine and coolant, and restarts the engine as necessary to maintain a temperature within a preset range. Engine manufacturers offer this option. The period of shutdown varies with the ambient temperature; in extreme weather, the engine may need to remain on most or all of the time. Cab-comfort services are available while the engine is on, but not while it is off.

Considerations: Idle management systems are inexpensive, but they offer minimal savings in extreme weather. The use of these systems may not ensure compliance with state idling restrictions. Intermittent engine noise and vibration may disturb the driver. Fuel use and emissions are avoided for the period that the engine is shut down only. Therefore, especially in extreme climates, these systems may produce less fuel savings (and emission reductions) than other types. Finally, such systems may become less available as new trucks increasingly come equipped with simple idle shutdown timers, which give manufacturers compliance credits under the EPA and NHTSA Phase 2 greenhouse gas standards.

\subsubsection{Heating Technologies}

Fuel-fired heaters are simple, compact, quiet, and lightweight devices (see Figure 3). Both cabin heaters that supply warm air to the cab/sleeper and coolant heaters that keep the engine block warm are available at low cost. Cab heaters can be coupled with air conditioners if the trucker's service area includes both cold winters and hot summers. The most common fuel used is diesel, although natural-gas-fired heaters are available for use in trucks fueled by natural gas; heaters can be easily retrofitted onto existing trucks. Electrical loads during engine-off periods must rely on the truck's batteries, leading to some concerns about restarting if many appliances are in use. However, if fuel-fired heaters are coupled with battery-powered air

2 Under Phase 2 of the EPA's and National Highway Traffic Safety Administration's (NHTSA's) Greenhouse Gas Emissions Standards and Fuel Efficiency Standards for Medium- and Heavy-Duty Engines and Vehicles [hereafter referred to as Phase 2 standards], published in August 2016, manufacturers seeking any IR compliance credits must, at a minimum, install idle shutdown timers. More credit is awarded for tamperproof idle limiters and the addition of other IR technologies. 
conditioners, the air conditioner batteries can supply sufficient auxiliary power during heater use. Fuel use and emissions by fuel-fired heaters are very low, typically under $10 \%$ of those from idling of trucks produced through 2006 , because they supply heat directly from a small combustion flame to a heat exchanger. Fuel-fired heaters can be used in emergencies for cold-weather survival.

Considerations: Fuel-fired heaters use very little fuel, have low emissions, are quiet, and have fast payback for drivers who have a regular need for heat.

Heat recovery systems are simple and inexpensive IR devices, requiring only about a $\$ 600$ investment. These consist of a small electrical pump installed in the truck's cooling system to circulate the coolant from the hot engine to the existing heating system's heat exchanger and a fan to supply heat to the driver's compartment. The only energy use is

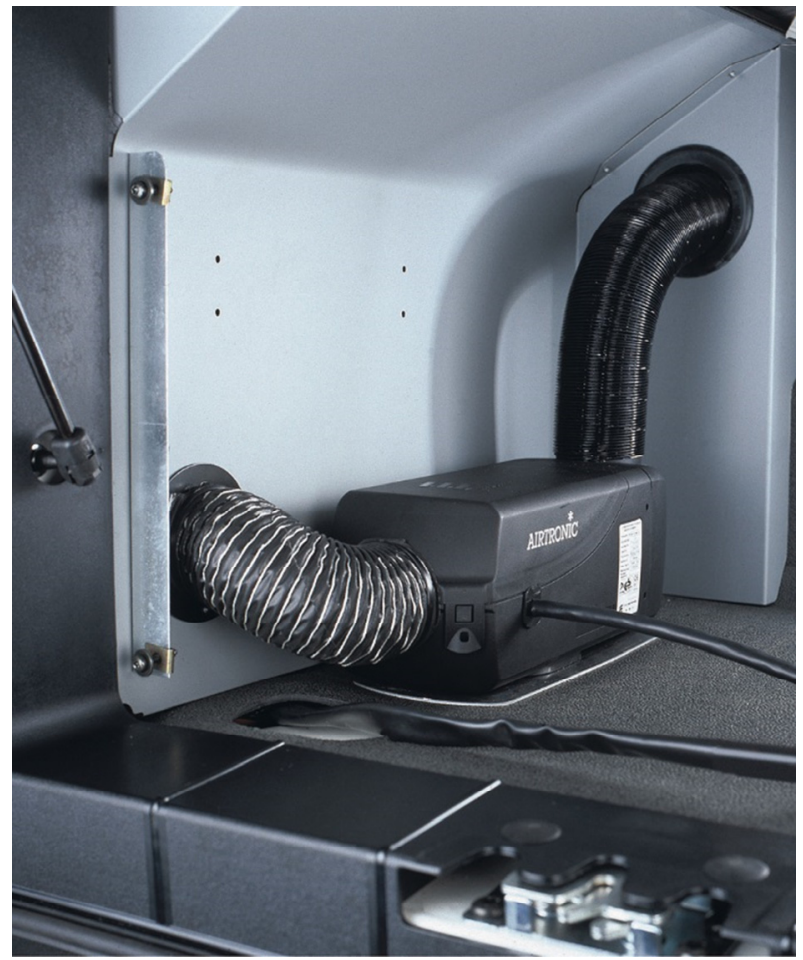

FIGURE 3 Airtronic D2 Bunk Heater (Photo: Courtesy of Espar) a small amount of electricity to run the pump and fan. The system also serves to blow hot air out of a stopped vehicle during the summer. In addition, it includes sensors to shut it off when the engine cools below $95^{\circ} \mathrm{F}$ or the battery voltage is low; engine hot spots after shutdown are thus avoided.

Considerations: At $15^{\circ} \mathrm{F}$ in a 4-knot wind, the cabin of a Class 8 truck can be kept warm by a heat-recovery system for about 4 hours (Boyer 2006). This is adequate for avoiding workday idling for heat by a day cab, but insufficient to keep sleeping long-haul drivers warm overnight. This system is also used in smaller vehicles, such as utility and law-enforcement vehicles.

\subsubsection{Cooling Technologies}

Air conditioners can be installed alone, or in conjunction with heaters. They are suitable for cooling in all warm weather (regardless of humidity). Various technologies can be used, from thermal storage to battery-electric, to vapor compression to heat pumps. Prices currently average around $\$ 8,600$. Additional costs may be incurred after several years to replace the batteries or other components. Several systems currently on the market provide cooling with lightweight units (70-90 lb) mounted on the cab roof or under the bunk. They can be run off the truck's existing batteries or from additional batteries (adding weight), or from thermal storage (also adding weight). In either case, the energy for cooling is supplied to the storage device when it is recharged by the truck's engine during operation. The engine uses a small quantity of extra fuel 
for this; however, the emissions from burning this fuel are on the highway, not at the truck stop or depot. An inverter/charger may be required to charge the batteries.

Considerations: Storage cooling has low maintenance costs and emissions, but the devices may be heavy, and typical battery life is 2 years. For battery-electric air conditioners, lithium-ion battery technology reduces weight and increases life but at higher cost. Many storage-cooling options are plug-in capable. Because storage cooling may provide cooling for only 8 to 10 hours, it cannot be relied on to provide full service for a 34-hour restart period unless it can be plugged in or recharged by idling the engine (1-3 hours) (NACFE 2014a). Solar panels can provide additional battery charge. Storage cooling may require a larger alternator (NACFE 2014a).

Evaporative ("swamp") coolers are inexpensive (some less than $\$ 1,000$ ) and can be used while the vehicle is stopped, or while it is operating, as primary or supplemental air-conditioning. Air blown across the surface of water from the device's reservoir (which must be refilled periodically) evaporates some of the water, which thereby removes heat from the air. Unfortunately, the rate of evaporation decreases as the humidity rises, so evaporative cooling is only effective in dry climates where the ambient humidity is low. The only energy use by swamp coolers is the small amount of electricity needed to pump the water and run the fan (requiring $112-\mathrm{V}$ battery for 8 hours of use). Total weight for a cooler with a full water reservoir is about $125 \mathrm{lb}$.

\subsubsection{Auxiliary Power Units}

Auxiliary power units usually consist of a small diesel-fueled engine that powers a generator to provide electricity and heat; the unit is mounted on the truck's frame rail (see Figure 4). Battery-powered units are also increasingly available, and some fuel cell units have been developed. Battery APUs are essentially battery-electric air conditioners integrated with heaters. There is concern that battery APUs cannot supply service for an entire 34-hour restart period unless they can be plugged in to run on grid power. APUs supply cab/sleeper heat with an electric heater or a diesel-fired heater. Engine coolant may be circulated for additional heat. A separate air-conditioning unit is normally installed in the sleeper area, although some units use the truck's existing air-conditioning system. These units supply all of the services the trucker requires to be comfortable in any weather-heat (bunk and engine), air-conditioning, and electric power for lighting and appliances. APUs can also serve as survival systems in emergencies.

Fuel consumption for the APU is about a factor of 4 smaller than that for the idling truck.

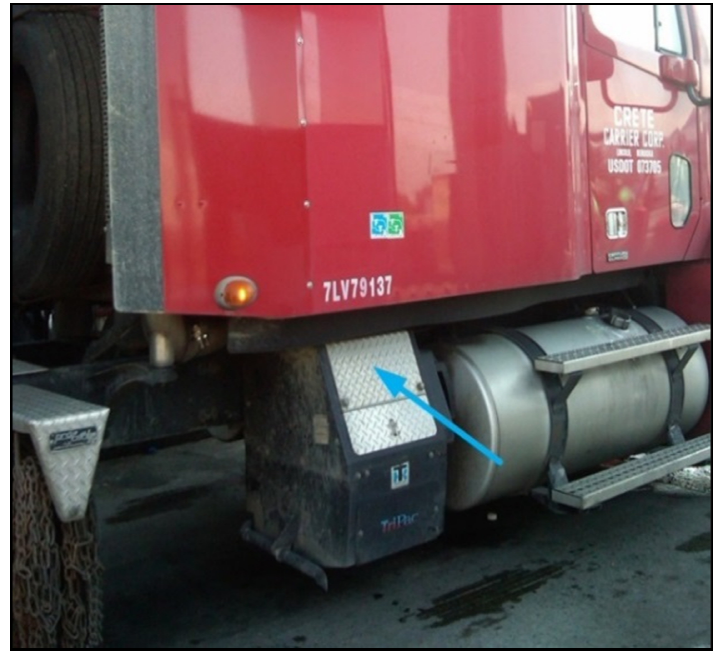

FIGURE 4 Diesel APU (Photo: Courtesy of Terry Levinson) 
Fuel use varies by season and design, with direct heating consuming under 0.1 gallon per hour and air-conditioning up to 0.25 gallon or more per hour. Installed costs for retrofitted units range from $\$ 7,500$ to $\$ 12,000$, depending on the design. Although truck manufacturers do not routinely supply APUs on new trucks, several manufacturers now offer this option. Phase 2 standards will provide the incentive for manufacturers to install battery APUs but not diesel ones. Both original equipment manufacturer (OEM) installation and fleet purchase are expected to reduce the cost. OEM-installed units may also be lighter than retrofitted units and likely designed for service at the same time as the engine.

Considerations: APUs have an initial high cost and are heavy, although most states have weight exemptions for APUs (see energy.gov/eere/vehicles/map-state-recognition-auxiliarypower-weight-exemption). Diesel APUs are quieter than the main engine, but noisier than heaters. Initial concerns about maintenance intervals not matching those of the truck itself, and about the availability of parts and service for the units on the road, are diminishing as more units are sold. For truck model years 2010 and newer, idling emissions are so well controlled that a diesel APU's particulate matter (PM) emissions (regulated under less stringent small engine standards) will actually be higher than the truck engine's emissions (Gaines and Burnham 2016). In California, diesel APUs on trucks newer than model year 2007 must be equipped with their own diesel particulate filters. Phase 2 standards will require PM controls on diesel APUs installed on model year 2018 and later trucks, but they do not provide credits for diesel APUs. This will be both a cost and a credit penalty for diesel APUs compared to battery APUs.

\subsection{WAYSIDE POWER}

\subsubsection{Electrified Parking Spaces}

Electrified parking spaces allow parked vehicles access to electrically supplied heating, cooling, and other services. This type of system is often referred to as truck stop electrification (TSE). Some industrial stakeholders object to this term, however, because it implies that the applicability is limited to truck stops. The user pays an hourly fee for plugging into the service. These wayside units have the advantage of adding little or no weight to the truck and causing no local emissions because no diesel fuel is consumed. There are, of course, upstream emissions from generating the electricity and producing and transporting the power plant fuel (Gaines and Brodrick 2009). However, wayside units have the disadvantage of being available only at truck stops or other depots where they have been installed. Even if such installations are eventually widespread, there will be times or places where a trucker is unable to find a place to plug in, and will therefore need to idle, forego cab comfort, or utilize an alternative IR device.

Two basic types of wayside units have been developed and deployed for supplying power and hotel services to trucks at rest. One is a "single" system that supplies all needed services (from equipment on the ground) through a duct inserted into the cab window. The other, "dual" system electrification, is a pedestal-mounted electrical outlet at a parking spot that allows the trucker to tap into the electric power grid to power electrical equipment on the truck. As of this writing, the dual system is more widespread but gets little use (see Section 2.2.1.2). EPS works 
ideally for trucks that travel repeatedly to the same destinations, as demonstrated by recent installations at truck terminals.

\subsubsection{Single-System Electrification}

This concept requires no retrofit of the truck and therefore essentially no up-front cost to the user. The only equipment required on the truck is an inexpensive window template. An electrical heating, ventilation, and air-conditioning (HVAC) unit that produces the conditioned air is installed on a gantry (or pedestal) at the front of the parking space; conditioned air and electricity are fed through a filtered conduit ending in a service module that fits into the template (see Figure 5, Left). The service module includes a computer screen and access to the Internet, phone, and cable television in addition to electric power. These services are generally included in the hourly fee, which is currently about $\$ 1.85$. Other services, such as pay-per-view, are available for an additional charge. Installation was completed at more than 100 sites, but subsequent consolidation reduced the number to fewer than 40 .

\subsubsection{Dual-System Electrification}

The trucker "plugs in" the truck to an outlet at the truck stop or depot to power on-board equipment (Figure 5, Right). The current hourly charge is $\$ 1.00$. Electrification involves modifying the parking location by installing ground electric outlets at each parking space. Currently, there are about 62 truck stops across the United States that provide plug-in power, as shown in Figure 6. The locations shown in red include provision to plug in an electric transport refrigeration unit ${ }^{3}$ (e-TRU). Dual-system electrification can involve some combination of an inverter/charger, electric engine block heater, electric fuel heater, and electric heating/cooling device for cab and sleeper air-conditioning, and electric idle control on the truck. The equipment may be retrofit or part of the original equipment. The cost depends on the equipment installed. A battery-electric HVAC unit, which is not dependent on wayside power if sufficient battery charge is available, will cost more than $\$ 8,000$ installed. A simple plug-in electric HVAC with an inverter/charger might cost about $\$ 2,500 .^{4}$

3 TRUs are sometimes called reefers.

4 In a related effort that could make dual-system electrification easier to adopt, engine manufacturers are replacing engine shaft-driven pumps and accessories with electrically driven devices that operate on demand, thereby reducing parasitic loads. DOE supported research on the MorElectric ${ }^{\mathrm{TM}}$ Technology concept, in partnership with Caterpillar Inc., International Truck and Engine Corporation, and Cox Transfer, Inc. DOE's SuperTruck Program has demonstrated the technical viability of these devices on an integrated total system level (Gibbs 2016). 


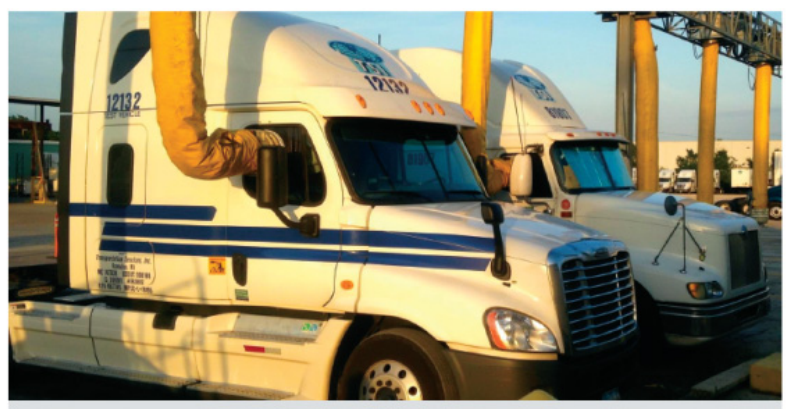

With single-system EPS, a truck driver attaches a duct that provides heated or cooled air to the truck. Power outlets and amenities such as internet access may also be provided. Used with permission of IdleAir.

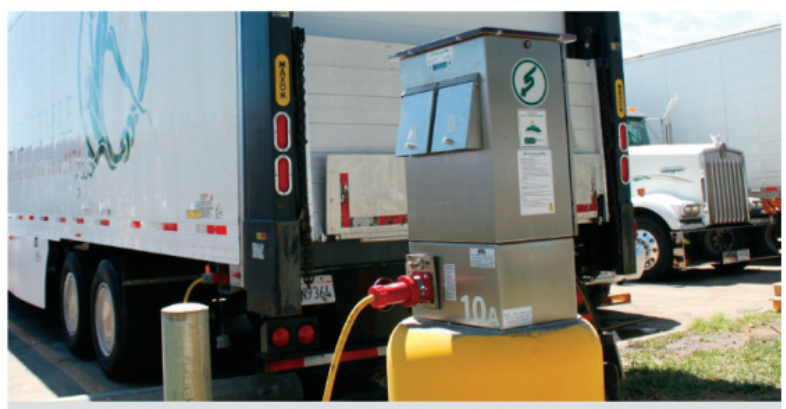

With dual-system EPS, a truck driver plugs in to power an on-board APU, air conditioner, or heater. Some sites offer the higher-voltage power required for trailer refrigeration, as shown here. Used with permission of Shorepower Technologies.

FIGURE 5 Single-System EPS (Left) and Dual-System EPS (Right)

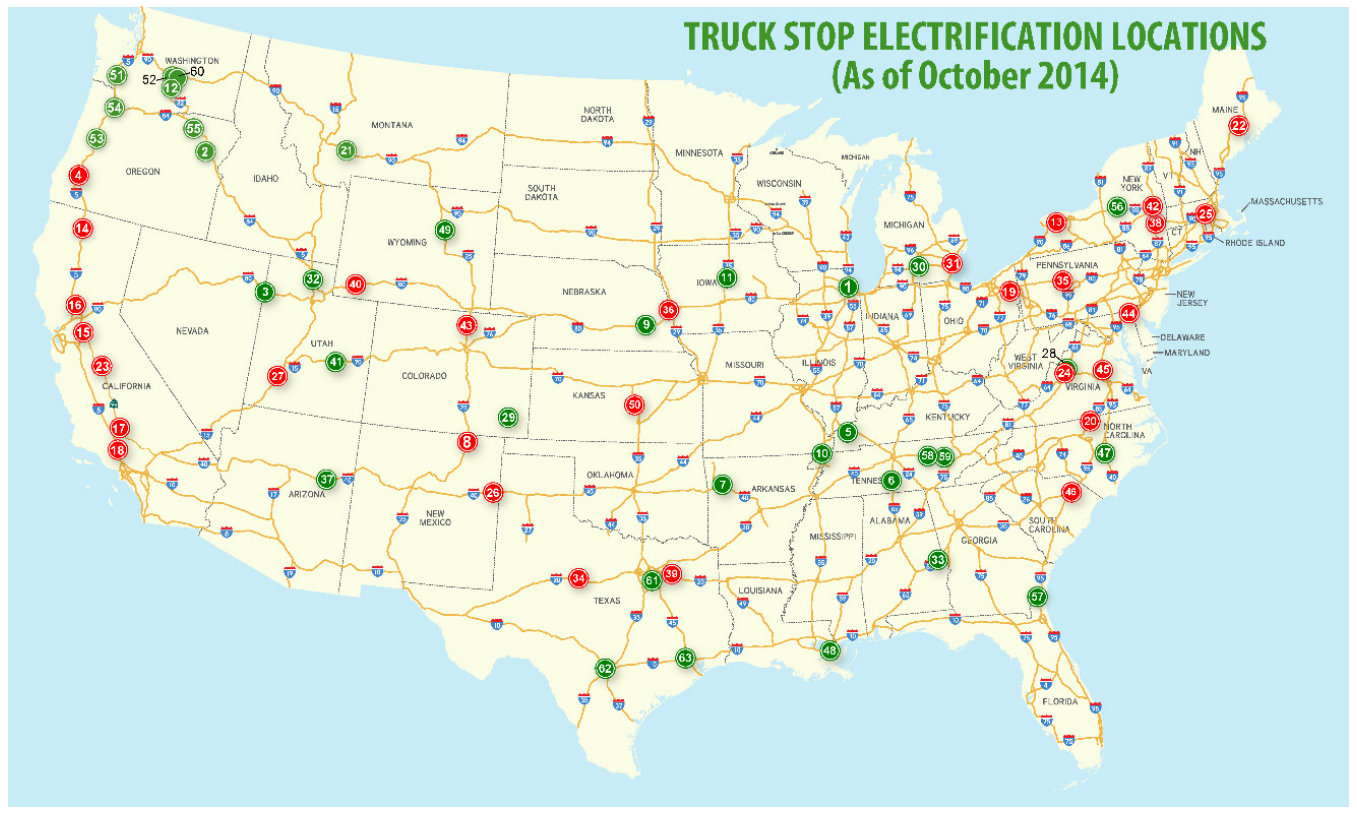

FIGURE 6 Shorepower Locations (Courtesy of Shorepower)

Considerations: Because an EPS runs on electricity rather than diesel fuel, there are no emissions at the point of use. Single-system EPSs are popular for supplying air-conditioning on very hot nights, but availability is limited. That means that drivers must have another way to supply cab comfort if an EPS is not available. Single-system EPS also offers a power-only option, at a lower hourly rate, to allow drivers to plug in to a simple $\$ 25$ electric resistance heater in the winter. Some company drivers have expressed reluctance to use an EPS if they have to pay out of pocket and request reimbursement. For the EPS equipment owner, a high occupancy rate is needed to provide good return on investment (ROI). EPSs have been installed successfully at several dedicated fleet terminals. 


\subsection{MARKET PENETRATION}

Solid data about the use of IR technologies in any vehicle type are hard to find; longhaul, heavy-duty trucks with sleeper cabs are no exception, because no trade association or government agency tracks overall usage of IR devices. The 2002 VIUS estimated that IR equipment was installed on 126,000 tractor-trailers (USCB 2002), and a 2006 report by the ATRI indicated that equipment was installed on $36 \%$ of its small sample (ATRI 2006); no comprehensive data are available. In its 2014 report on IR for heavy-duty, long-haul trucks, Confidence Report: Idle-Reduction Solutions (NACFE 2014b), Trucking Efficiency, a partnership of the North American Council for Freight Efficiency (NACFE) and the Carbon War Room, reported that of the fleets it surveyed, idling times ranged from $7 \%$ to $40 \%$, with an average of 15\%. NACFE's 2016 Fleet Fuel Efficiency Benchmark Study (NACFE 2016) gives a broad picture of IR equipment use in sleeper trucks (Figure 7).

For sleeper-truck IR technologies, market penetration has been slow for a variety of reasons. In many cases, the cost and ROI, or perceived ROI, have not been sufficiently favorable. Money for purchase and installation may be tight, and the grants made available through the American Recovery and Reinvestment Act (ARRA) of 2009, which reduced purchase and installation price and improved the ROI, are no longer available. Funding opportunities continue but are smaller in scope and are usually found at the state or local level. These opportunities are

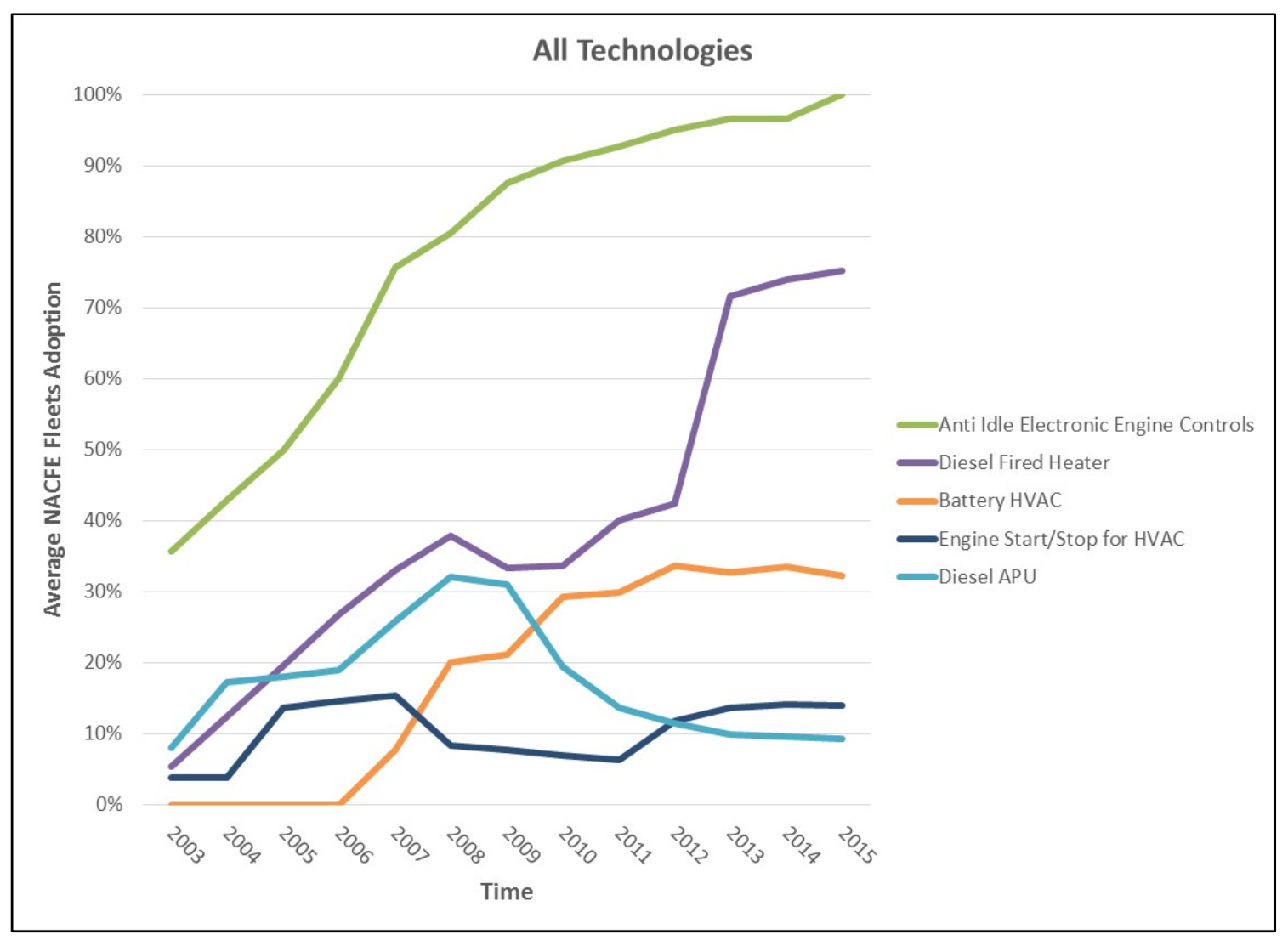

FIGURE 7 NACFE Fleets Adoption of IR Technologies (Source: NACFE 2016) 
tracked in the DOE Vehicle Technologies Office's monthly, electronic newsletter, National Idling Reduction Network News (http://energy.gov/eere/vehicles/vehicle-technologies-officenational-idling-reduction-network-news). In addition, some technologies did not perform as anticipated or required more maintenance than expected. Finally, some devices were installed that were not good fits with the vehicles' stationary power needs, and were thus found to be unsatisfactory. Phase 2 standards may encourage OEM installation of battery-powered APUs.

\subsection{DEVICE COSTS AND ENERGY CONSUMPTION}

Although all IR devices reduce fuel use compared to engine idling, their energy consumption is not negligible. Energy use varies by device and with conditions. Some devices use diesel fuel (or natural gas if the truck runs on compressed natural gas [CNG] or liquefied natural gas [LNG]), while others may use electricity from the grid. In that case, there are no local emissions from the truck when it is parked. Table 1 provides estimated fuel use for various IR devices, as well as their estimated capital cost (for on-board devices) or hourly charges for EPS. The table also estimates simple payback times for typical users; the Appendix describes how a user can estimate his/her own payback time for any device.

TABLE 1 Cab Comfort Options for Heavy-Duty Trucks: Fuel Use, Costs, and Typical Payback

\begin{tabular}{|c|c|c|c|c|c|}
\hline Power Source & Services & $\begin{array}{l}\text { Fuel Use } \\
\text { (gal/h) }\end{array}$ & $\begin{array}{c}\text { Typical Equipment } \\
\text { Cost }(\$)\end{array}$ & $\begin{array}{c}\text { Charge } \\
(\$ / \mathrm{h})\end{array}$ & $\begin{array}{l}\text { Typical } \\
\text { Payback } \\
\text { (yr) }^{\mathrm{a}}\end{array}$ \\
\hline Idling & All & $0.6-1.5$ & NA & NA & $\mathrm{NA}^{\mathrm{b}}$ \\
\hline APU & All & $0.2-0.5$ & $7,500-12,000^{c}$ & NA & 3.6 \\
\hline Diesel-fired heater & Heat & $0.04-0.08$ & $900-1,500^{\mathrm{c}}$ & NA & 0.6 \\
\hline Heat recovery & $\begin{array}{l}\text { Heat (limited } \\
\text { duration) }\end{array}$ & Negligible & 600 & NA & $<1$ \\
\hline Storage cooling & $\begin{array}{l}\text { Air- } \\
\text { conditioning }\end{array}$ & 0.15 & $8,500-8,800^{\mathrm{c}}$ & NA & 5 \\
\hline $\begin{array}{l}\text { Automatic engine } \\
\text { start/stop system }\end{array}$ & $\begin{array}{l}\text { All } \\
\text { (intermittent) }\end{array}$ & 0.25 & $1,500-2,500^{\mathrm{c}}$ & NA & 1 \\
\hline EPS (single system) & All & NA & $5^{\mathrm{d}}$ & $1.85^{\mathrm{e}}$ & NA \\
\hline EPS (dual system) & All & NA & Up to $2,500^{\mathrm{d}}$ & 1.00 & 1 \\
\hline
\end{tabular}

a Assumptions for payback: \$3/gal fuel, $1,800 \mathrm{~h} / \mathrm{yr}$ idling, $0.8 \mathrm{gal} / \mathrm{h}$ for idling; $0.3 \mathrm{for}$ APU; mid-range equipment prices; heat and air-conditioning each run $6 \mathrm{mo} / \mathrm{yr}$; vehicle fuel economy $7 \mathrm{mpg}$; auto start-stop assumed to run engine $30 \%$ of stationary time. Changes in any of the assumptions (e.g., hours idled/yr) will affect payback time.

b $\mathrm{NA}=$ not applicable.

c Includes installation (NACFE 2014b).

d Cost for window adaptor for single-system EPS and cost for on-board equipment for dual-system TSE.

e This is a standard rate, but discounts are available for stays $>10 \mathrm{~h}$. In addition, power-only service may be available for $\$ 0.99 / \mathrm{h}$. 
There are actually ranges for the different parameters because of seasonal variations and differences among manufacturers and models; the numbers in the table are simply approximate single-truck retrofit values for users who do not have specific device information. We do not endorse any device and recognize that users will need to get quotes on the latest models before making decisions. These numbers are considered to be a good starting point for single-truck retrofit purchases. Installation on a fleet or as original equipment is likely to be at lower cost than for a single truck retrofit. Similarly, fuel use for the devices, or for idling tractors, will depend on the load put on them (see the bottom of the worksheet in the Appendix for the estimated idling fuel use under varying conditions). If the truck is operated in extreme conditions, fuel use and fuel savings are likely to be higher than the typical values.

Costs tend to increase along with quality of service provided, so owners must evaluate their needs carefully before selecting equipment. We describe the different types of equipment and compare their characteristics, and we provide information to allow a purchaser to determine the type of system that best suits his/her needs, but we do not attempt to evaluate different products. Although we use data from specific equipment for the generic comparisons, this should not be interpreted as an endorsement of any manufacturer's product. Further, prices change over time, and this publication can only represent equipment costs as of the date of its preparation. 


\section{TOTAL COSTS AND PAYBACK FOR THE TRUCK OWNER}

This section examines how the costs to the truck owner vary as a function of fuel price and idling hours for competing IR technologies. It will be seen that options with high capital cost are generally more attractive for trucks that idle many hours per year, while options with a fixed cost-per-hour are more attractive for trucks that idle fewer hours.

Costs and fuel consumption were taken from Table 1. Capital costs were simply divided evenly over the first 5 years of operation. Heaters and air conditioners were each assumed to operate half the year. These simplifying assumptions do not significantly affect the relative positions of the different IR options. These results depend on the assumed hourly rate for EPS; numerous rates are available (see Table 2), depending on hours the equipment is used and other factors. Note also that single-system EPS rates often include TV service, and the value of this may be a consideration when choosing the best IR strategy for a truck.

The first consideration when choosing an IR strategy is the initial cost of the equipment. As can be seen in Figure 8, on-board systems that supply both heat and air-conditioning are expensive, on the order of $\$ 10,000$. Heaters are relatively inexpensive and will be seen to be an excellent option if all the driver needs at night is heat. Heaters are also considered in conjunction with APUs to reduce winter fuel costs (compared to APU use alone) and also reduce wear-andtear on the APU. Capital cost for the on-board equipment to be plugged into a dual-system EPS can be as high as $\$ 2,500$, if heat and air-conditioning are both required; a single-system EPS requires no equipment on the truck except a very inexpensive window template. An electric heater for use at the EPS can be purchased for about $\$ 25$.

The costs incurred by the truck owner to operate the IR equipment are proportional to the number of operating hours. For EPS, a fixed per-hour fee that does not vary with fuel price is charged by the system owner; this may decrease for stays over 10 hours. Costs to the system owner are discussed later, because they impact availability of the service. The APUs and air conditioners all require diesel fuel to run, so operating costs are directly proportional to diesel fuel prices, which are somewhat unpredictable. (Storage air conditioners and battery APUs use diesel fuel indirectly by taking energy from the engine as it runs down the road.) Thus,

TABLE 2 Rate Structure for Single-System EPS (Spring 2016)

\begin{tabular}{llccccc}
\hline \multicolumn{1}{c}{ Location } & \multicolumn{1}{c}{ Service } & HVAC & $\mathbf{1 2 0 - V}$ Power & TV & $\begin{array}{c}\text { Rate } \\
(\mathbf{\$} / \mathbf{h})\end{array}$ & Packages Available \\
\hline Truck stop & Premium & Yes & Yes & Yes & $\$ 1.85$ & $12 \mathrm{~h} / \$ 20,40 \mathrm{~h} / \$ 50$ \\
Truck stop & Power plus TV & No & Yes & Yes & $\$ 1.49$ & $10 \mathrm{~h} / \$ 12.50$ \\
Fleet terminal & Basic & Yes & Yes & No & $\$ 1.30$ & $-^{\mathrm{a}}$ \\
Fleet terminal & Power & No & Yes & No & $\$ 1.00$ & - \\
\hline${ }^{a}$ A dash indicates not applicable. & & & & & &
\end{tabular}




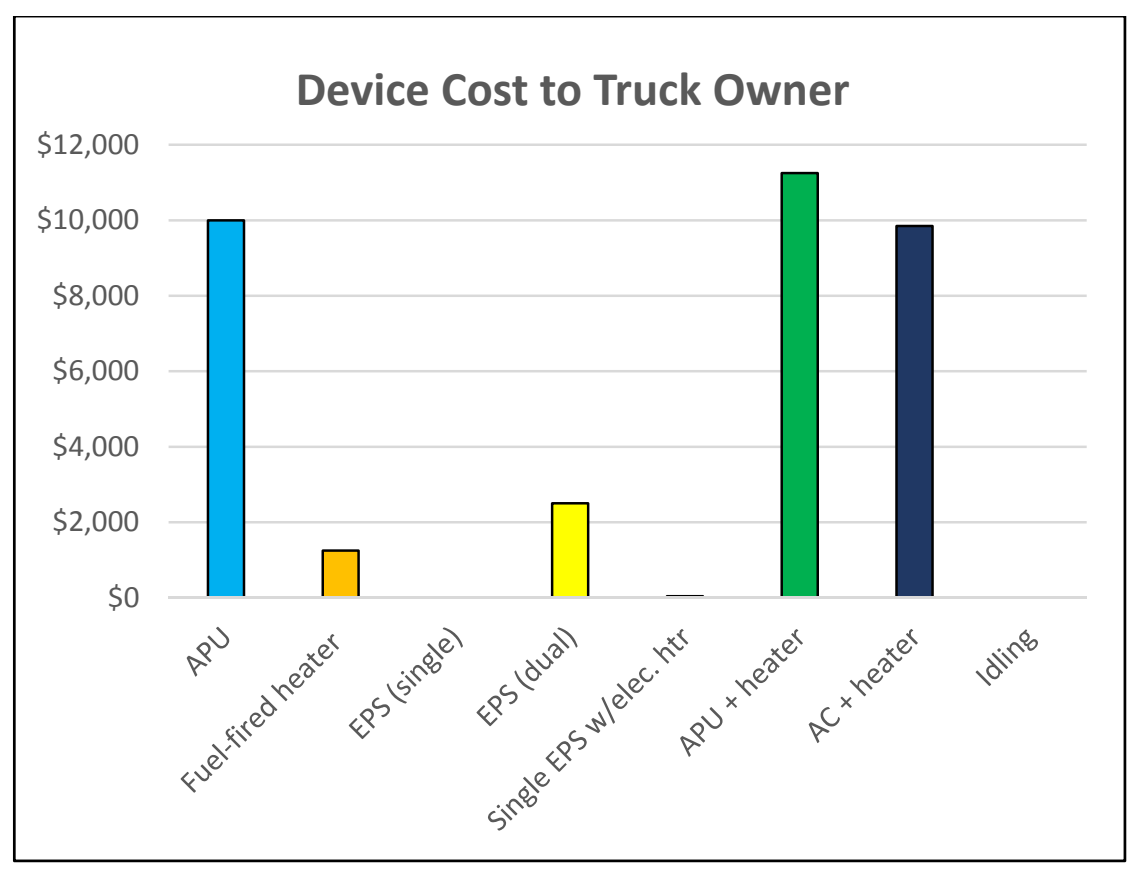

FIGURE 8 On-Board IR Equipment Capital Costs

sensitivity of costs to diesel price up to as high as $\$ 5 /$ gal is included in the discussion, covering all three of the Energy Information Administration's (EIA's) price projection scenarios, as shown in Figure 9. Diesel APUs and heaters burn diesel fuel while the truck is parked; the addition of a heater does reduce APU operating costs because it burns less fuel than the APU does. The hourly operating costs for idling and IR devices are shown as a function of diesel price in Figure 10. The first thing to note is that all IR options reduce operating costs compared to idling, as long as fuel price remains over \$2/gal. EPS operating costs are independent of fuel cost, but costs of using diesel-fueled devices rise with fuel price. For low fuel prices (up to $\$ 2.10 / \mathrm{gal}$ ), on-board heating and cooling devices have the lowest operating costs. A singlesystem EPS has the highest hourly operating cost of the IR options (but of course essentially zero capital cost); however, use of an inexpensive heater allows a trucker to purchase electric power only from the EPS in the winter, at a considerably lower rate. ${ }^{5}$ Rates at terminals may also be considerably lower. A dual-system EPS has still lower operating costs but does require an upfront investment.

Figures 11 and 12 illustrate how fuel price, here varied from zero up to \$5/gal, impacts the total cost incurred by a truck owner over a 5-year period for a truck that idles only 1,000 hours per year ("low idler") and one that idles 2,000 hours per year (about 40 hours per week, a "high idler"), respectively. It can be seen that a fuel-fired heater is always the least expensive way to supply heat. If air-conditioning is also required, idling is least expensive when fuel is under about $\$ 1.50 /$ gal, but most expensive for fuel over $\$ 4 /$ gal for low idlers or over

\footnotetext{
5 Assumed to be $\$ 0.99 / \mathrm{h}$. This rate may not actually be available, but power-only bundled with TV is currently available for $\$ 1.25 / \mathrm{h}$.
} 


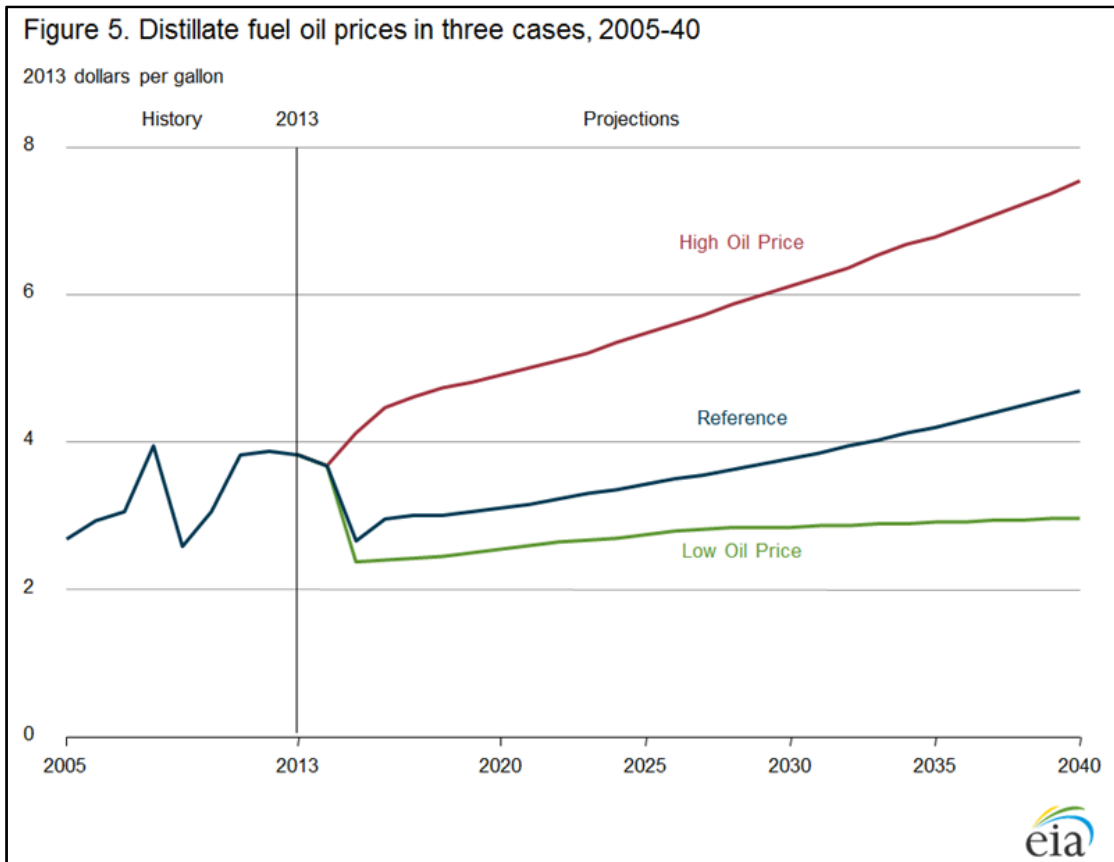

FIGURE 9 EIA Diesel Price Projections (Source: EIA 2016)

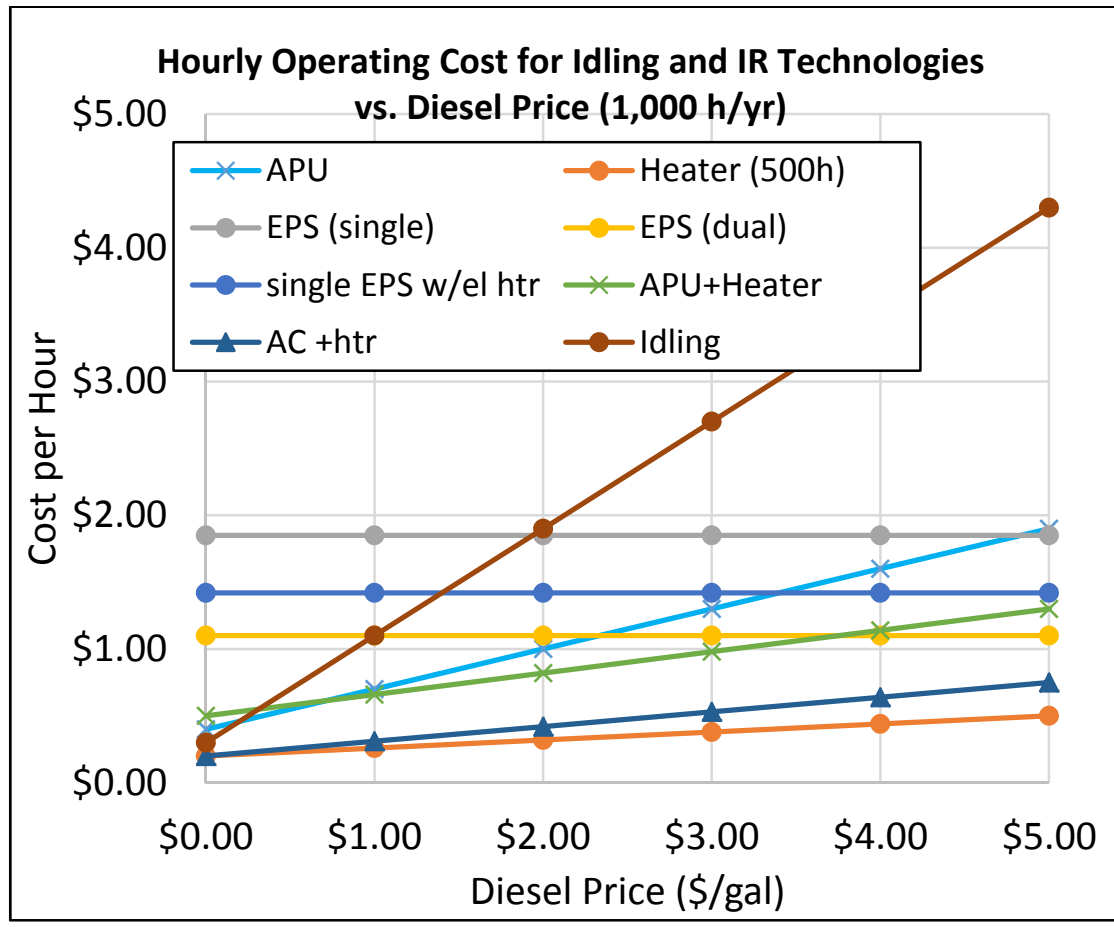

FIGURE 10 Operating Costs for IR Equipment, as a Function of Fuel Price 


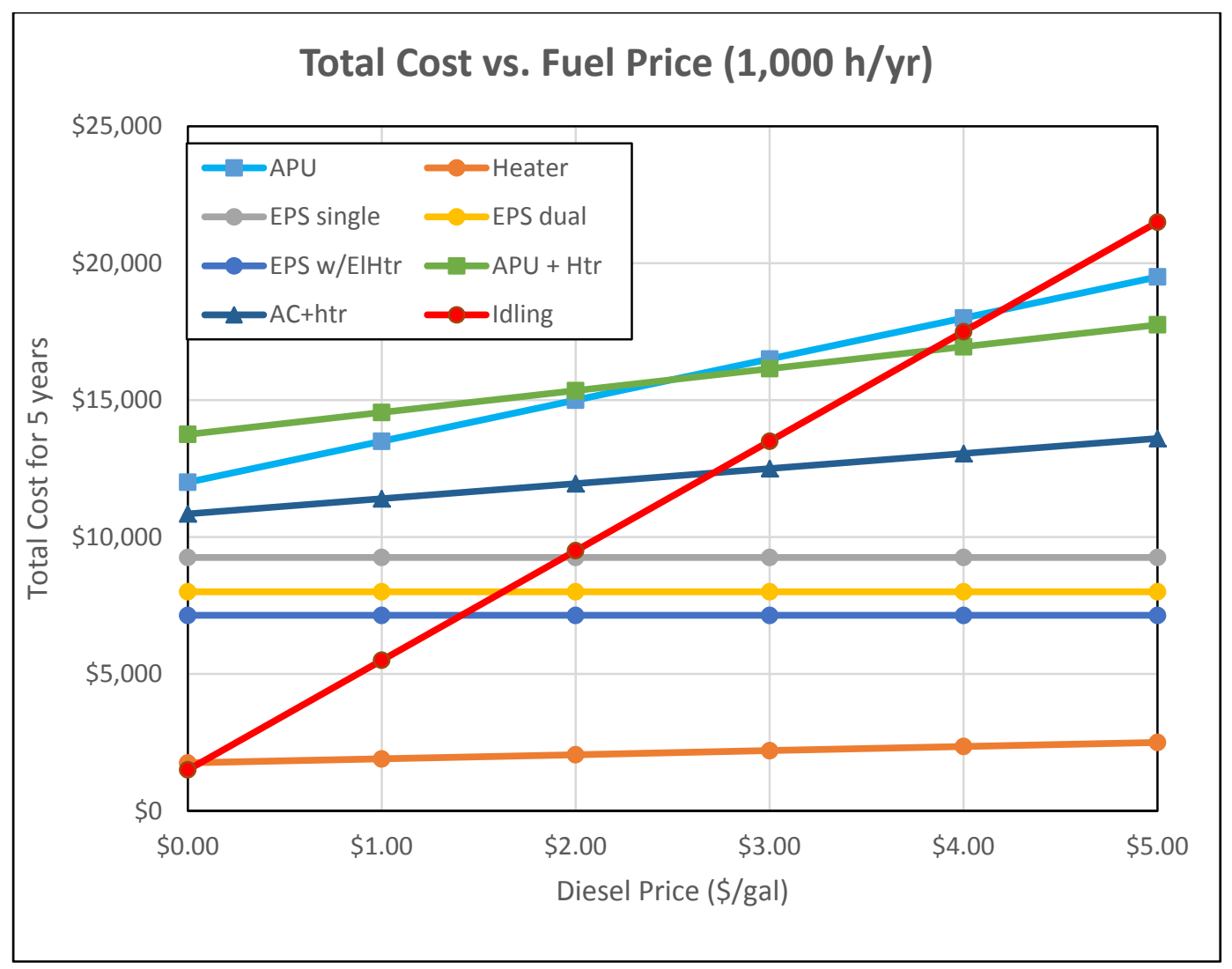

FIGURE 11 Total Cost over 5 Years as a Function of Fuel Price for Low Idlers

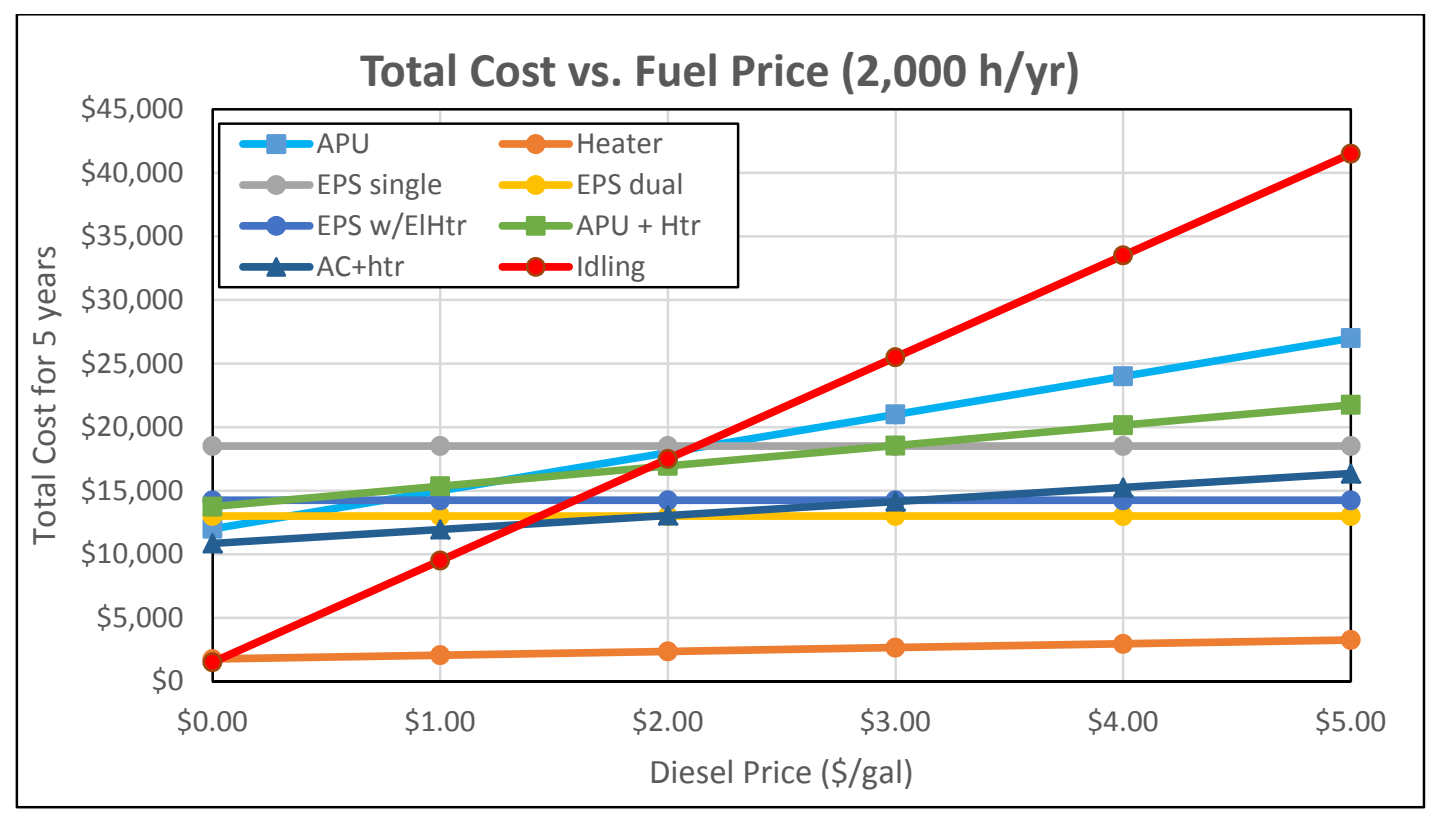

FIGURE 12 Total Cost over 5 Years as a Function of Fuel Price for High Idlers 
\$2/gal for high idlers. Of particular interest is the relative behavior of APUs and a single-system EPS. The addition of a heater and the use of a power-only option lower the total cost of the EPS considerably. Similarly, a diesel APU coupled with a fuel-fired heater supplies heat more efficiently. This adds to the capital cost but reduces fuel use, and makes little difference in total cost, except when fuel prices rise significantly. The EPS plus heater is the most economical fullservice option for low idlers, as long as fuel costs over about $\$ 1.60 /$ gal. A dual-system EPS is slightly less expensive for high idlers. Without the electric heater, a single-system EPS is less expensive than an APU for high idlers, over about $\$ 2 /$ gal, and an APU plus heater over \$3/gal.

Figures 13 and 14 show how the total cost to the truck owner over a 5 -year period depends on the number of hours idled, from 0 to 2,400 hours per year (48 hours per week). For Figure 13, the price of fuel was assumed to be $\$ 2.50 / \mathrm{gal}$, and for Figure 14, $\$ 5 / \mathrm{gal}$. Again, a fuelfired heater can be seen to supply heat most economically. A single- or dual-system EPS looks best for low idlers (where EPS is available), but APUs have lower hourly costs and start to look better as the number of hours rises and the capital cost is spread over more usage. APUs look better than a single-system EPS only over 2,100 hours per year at \$2.50/gal, but not at all if fuel is $\$ 5 / \mathrm{gal}$. At $\$ 5 / \mathrm{gal}$, the difference between the EPS and EPS plus heater is significant, as it is between the APU and APU plus heater. Basically, that means it is less expensive to get heat electrically (and even cheaper directly from fuel), but a lot more costly to supply air-conditioning. When comparing single- and dual-system EPSs to each other, we see that the dual-system has lower total costs for trucks that idle more than 588 hours per year. However, as will be discussed later, effective air-conditioning is at a premium, especially in the summer in the U.S. Southwest. Note that longer stays at single-system EPSs are currently eligible for reduced

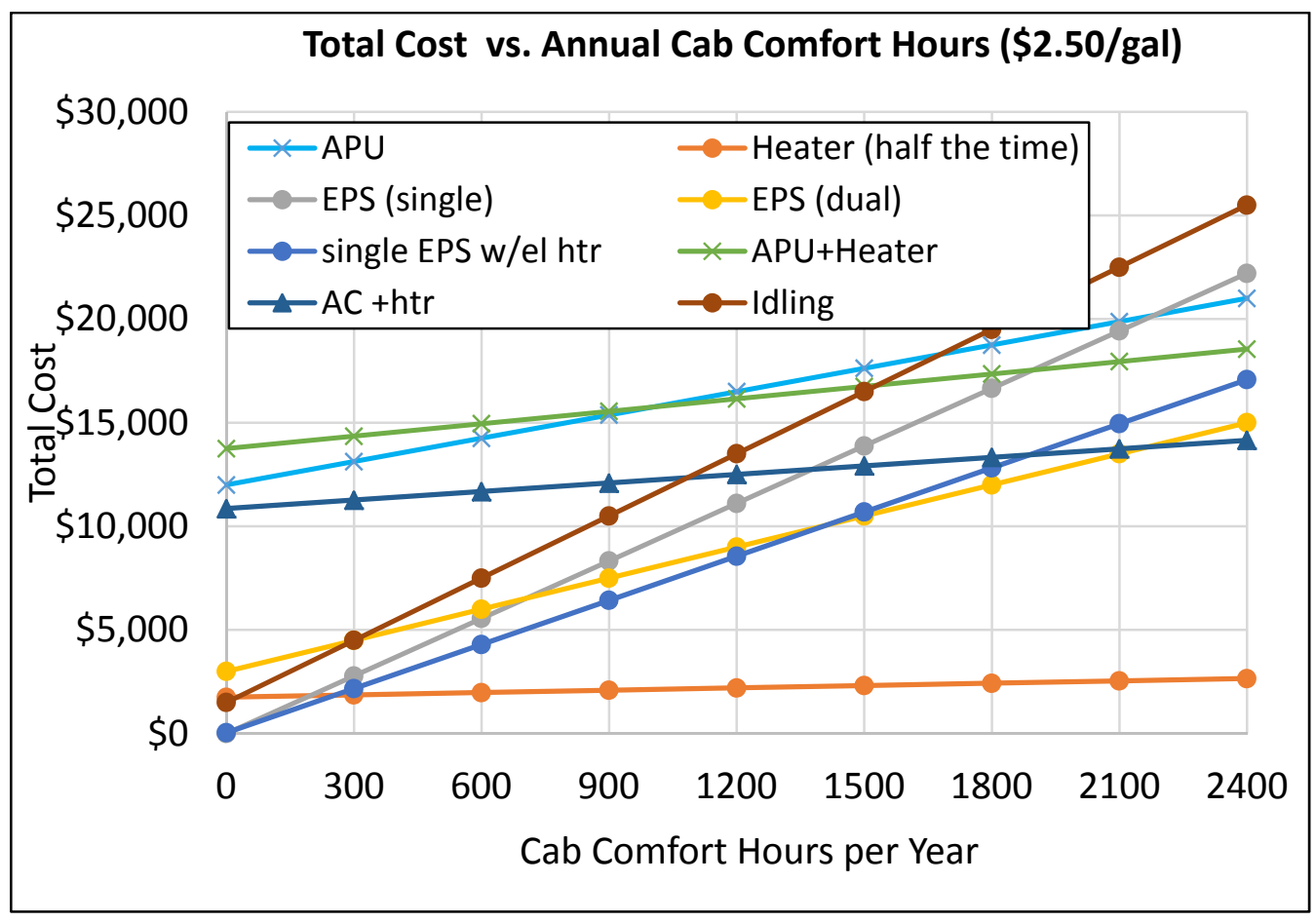

FIGURE 13 Total Cost over 5 Years as a Function of Idling Hours for Low Fuel Price 


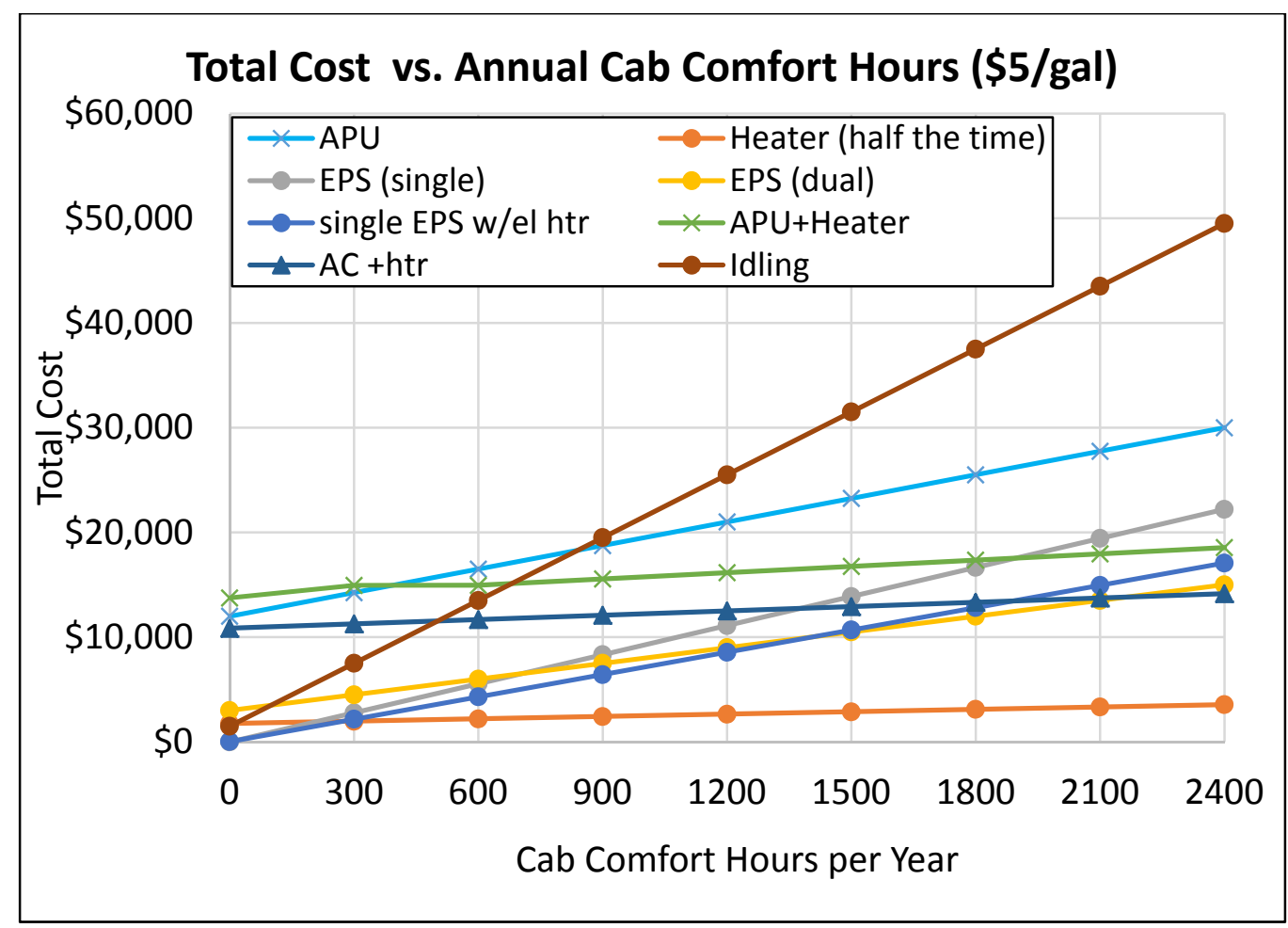

FIGURE 14 Total Cost over 5 Years as a Function of Idling Hours for High Fuel Price

rates, which would lower the total cost if the hours are accrued during stays of more than 10 hours.

It is apparent that supplying heat with a simple heater is beneficial in almost all cases. Here, we compare a diesel-fired heater, costing about $\$ 1,250$, with an electric heater $(\sim 25)$ plugged into an EPS at an hourly cost of $\$ 0.99 / \mathrm{h}$. Figure 15 shows that the electric heater incurs the least cost over 5 years only for heating of 300 hours per year or less ( 2 hours per day in winter), with the diesel heater's very low fuel cost, even at $\$ 5 /$ gal, quickly paying back its capital cost. This means that even many trucks that plan to use EPS for air-conditioning would save money by installing a diesel-fired heater for the winter. Note, however, that the diesel-fired heater supplies heat only, requiring lights and other electrical devices to run off the battery, while power for lights is included in the hourly fee for EPS power.

Thus far, we have only looked at the first 5 years of operation. The truck may not be kept in long-haul operation beyond that, but in hard times, it may, especially by owners and operators. If the truck does remain in operation after the capital cost of the equipment is paid off, the annual costs decrease, and it is much cheaper to operate an APU than to pay an hourly fee to the EPS owner, even at low operating hours, as shown in Figures 16 and 17. A paid-off APU is much less expensive to operate, regardless of the number of hours idled. This applies to one on an older truck, or one that is removed from an old truck and installed on a new truck for continued service. 


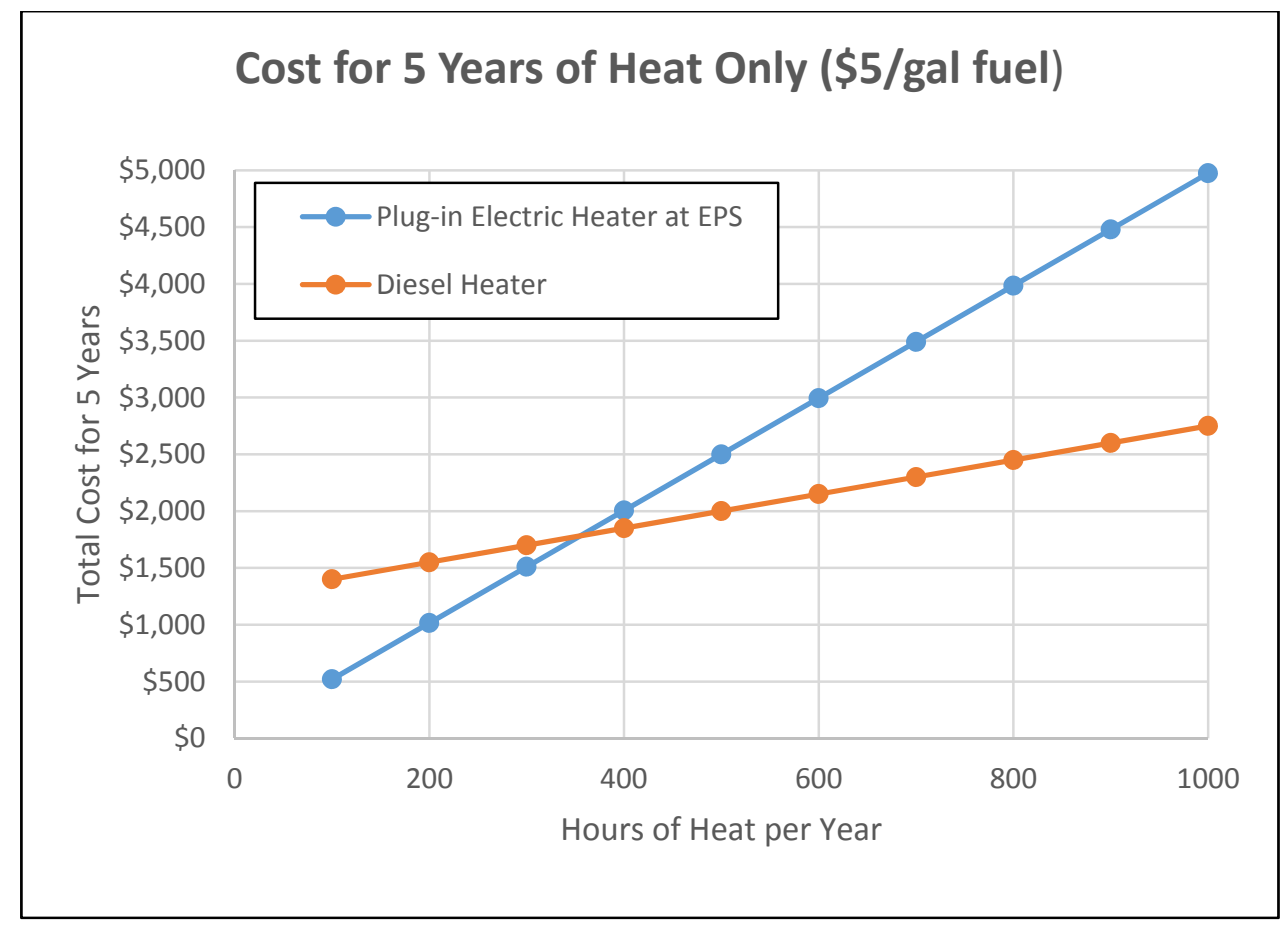

FIGURE 15 Total Cost for 5 Years of Heat Only

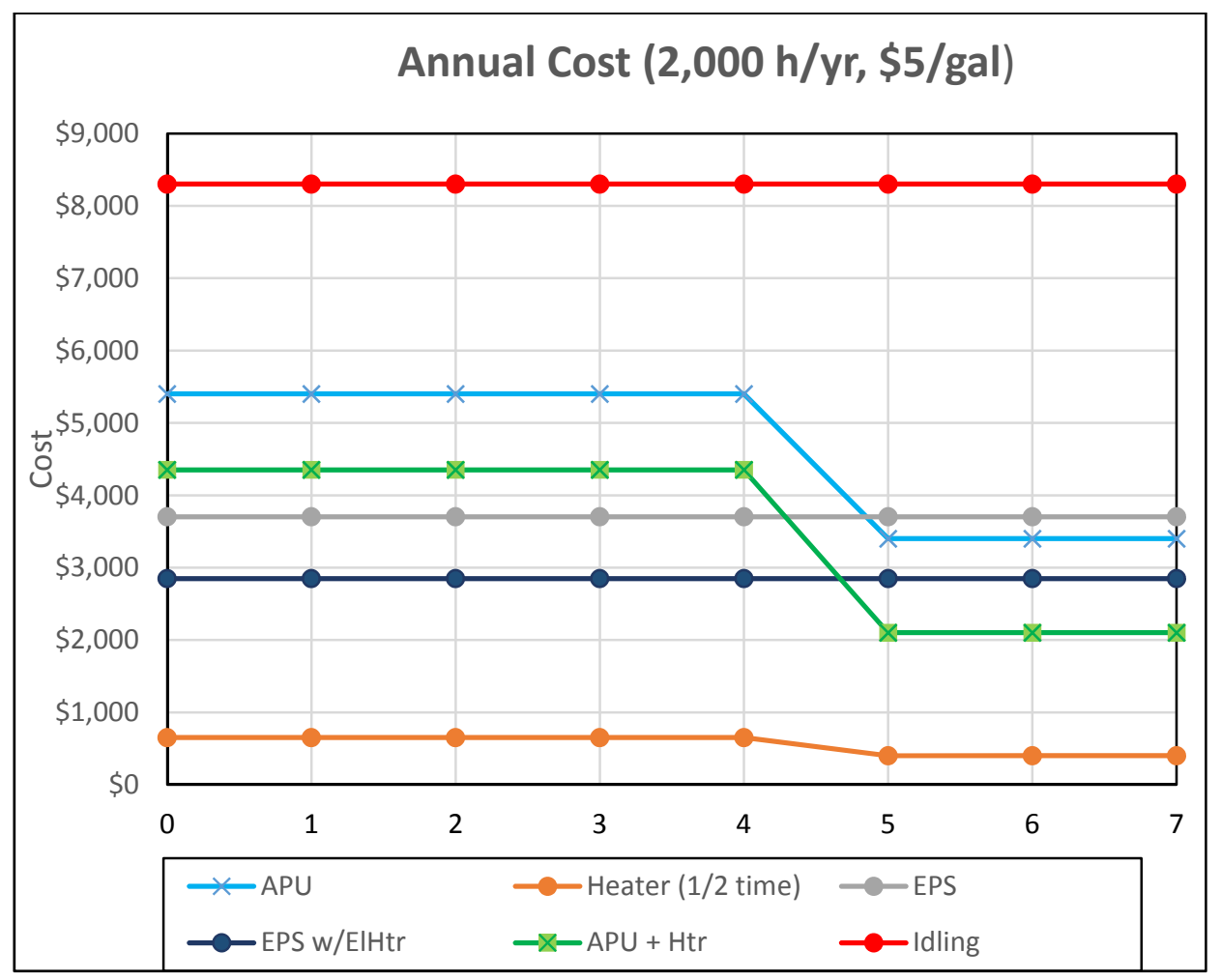

FIGURE 16 Annual Operating Costs as Equipment Is Paid Off, High Idlers at High Fuel Price 


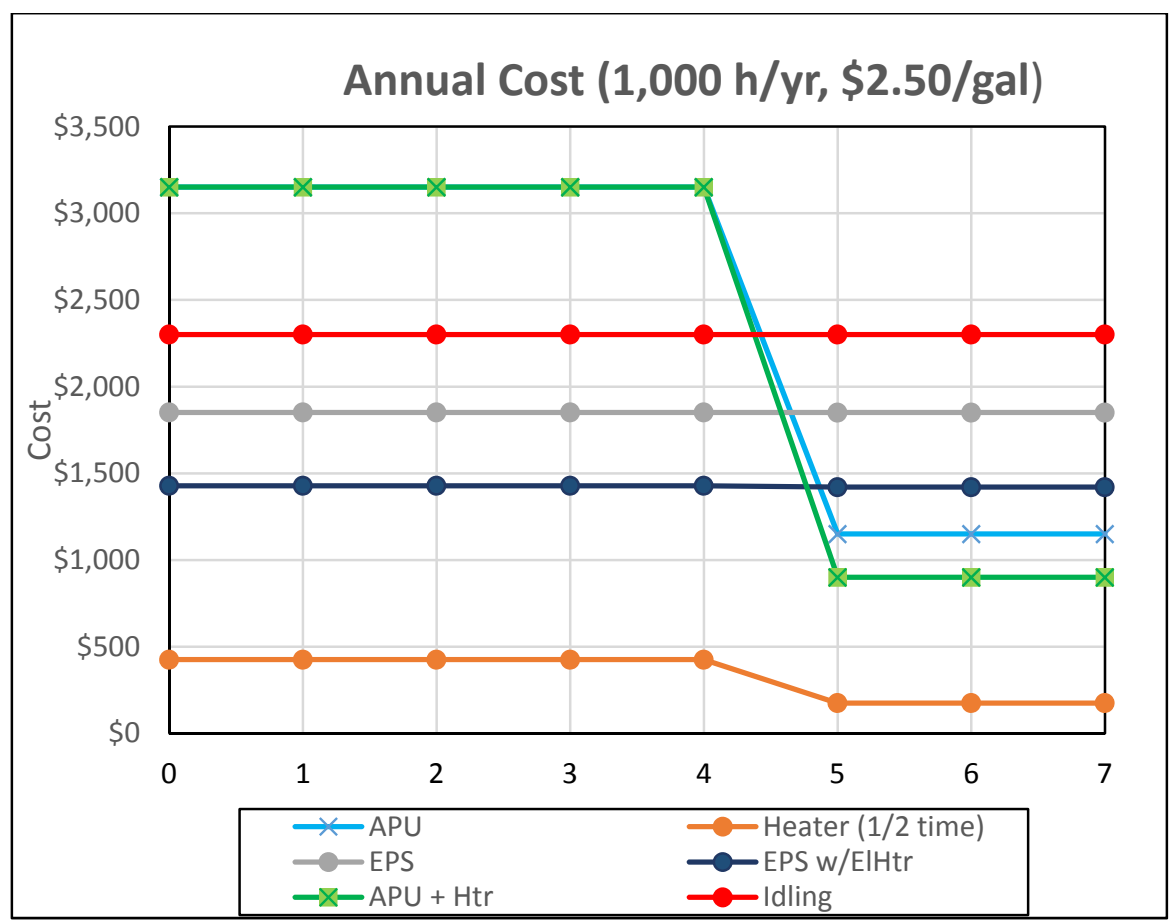

FIGURE 17 Annual Operating Costs as Equipment Is Paid Off, Low Idlers at Low Fuel Price

Figure 18 shows how simple payback on the initial capital investment varies as a function of fuel price, for a truck that idles 2,000 hours per year. It was calculated for each device and fuel cost using the worksheet in the Appendix. Even the costliest devices pay back in under 5 years at $\$ 2.50 / \mathrm{gal}$, and in 2 years if fuel goes back to $\$ 4 / \mathrm{gal}$. For high idlers, IR devices serve as insurance against high fuel prices. For low idlers (Figure 19), payback on on-board devices is very long. Note that the payback for a single-system EPS is essentially instant down to $\$ 2.10 / \mathrm{gal}$; below that, however, it never pays back compared to idling. 


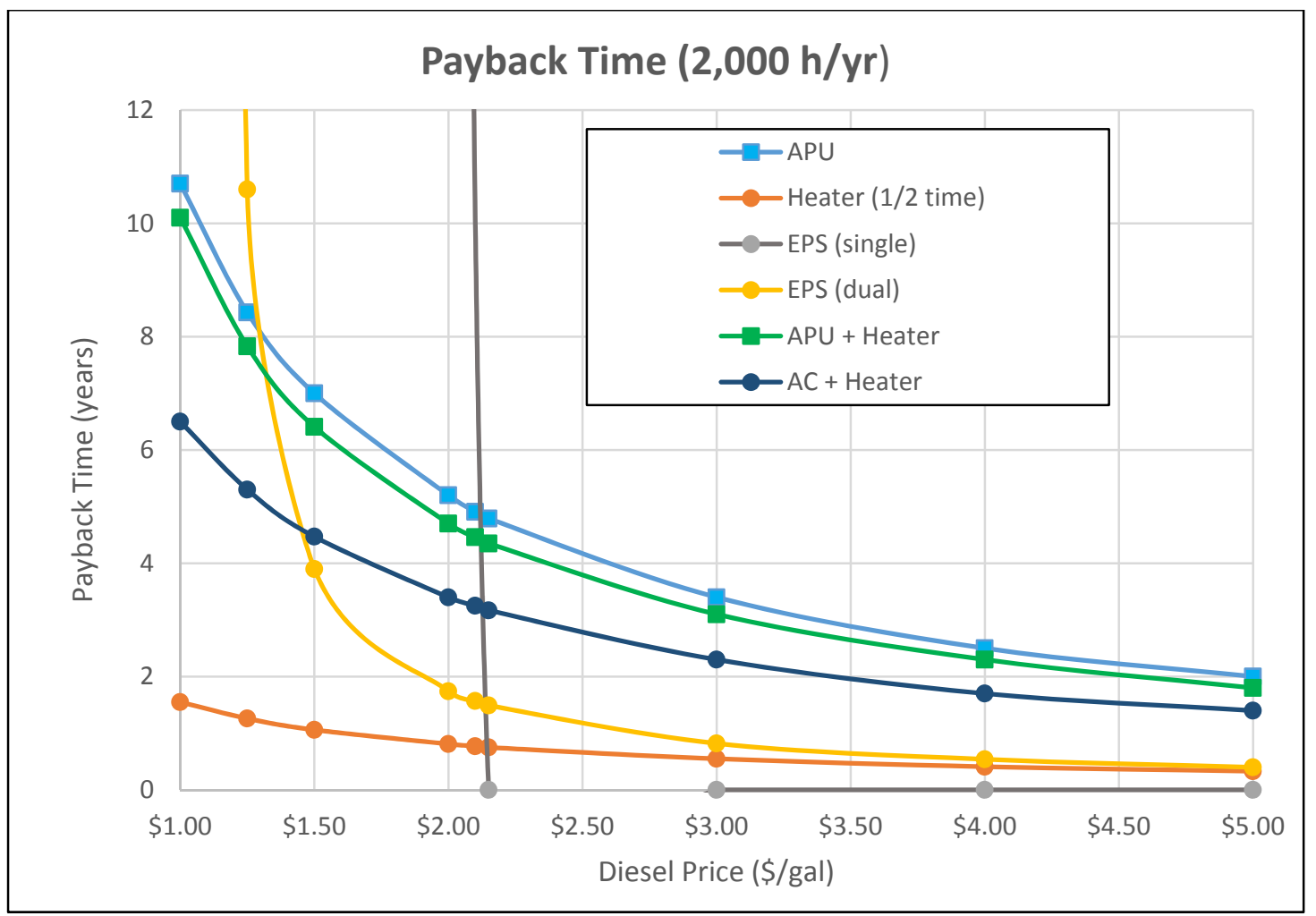

FIGURE 18 Equipment Payback Time as a Function of Fuel Price, High Idlers

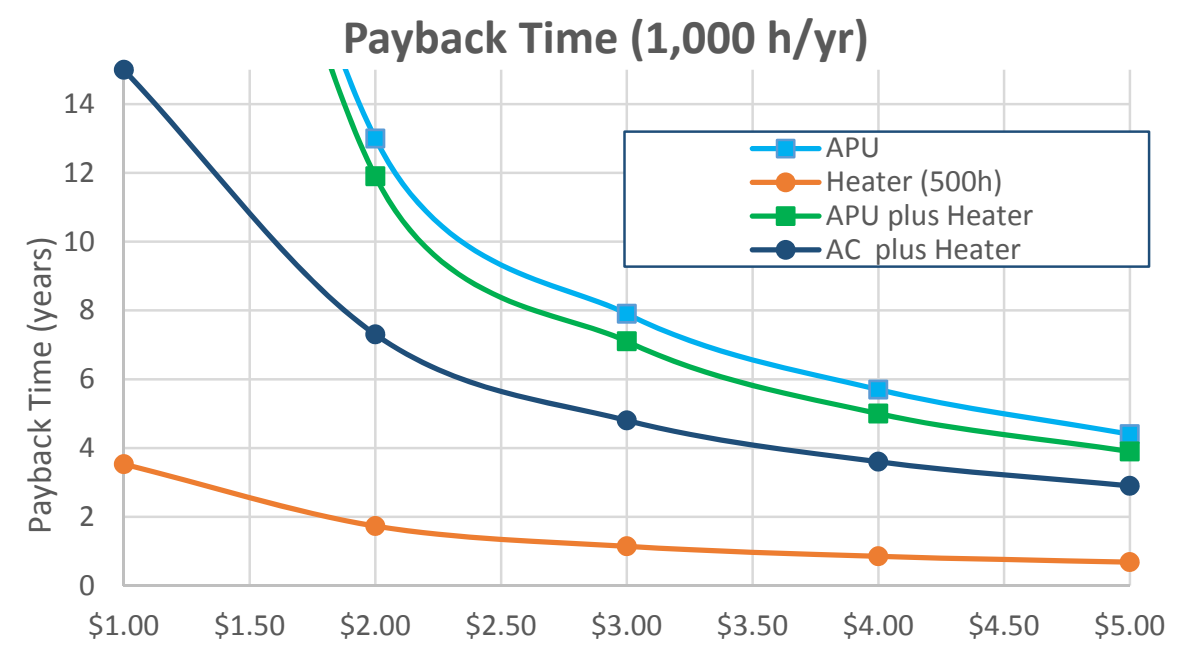

Diesel Price $(\$ / g a l)$

FIGURE 19 Equipment Payback Time as a Function of Fuel Price, Low Idlers 
This page left intentionally blank. 


\section{ECONOMICS FOR THE EPS OWNER}

The major purveyor of a single-system EPS has been able to bring the installed cost per space down dramatically by buying hardware in bankruptcy, streamlining construction complexity, narrowing the service offerings, and changing its parking lot configurations. Total cost per gantry space for the next 5,000 spaces will be less than half the $\$ 16,700$ /space incurred by the original company. Straight electric pedestals with brand new equipment will cost under $\$ 5,000 /$ space. At fleet terminals, gantry construction costs will be under $\$ 5,000 /$ space because less space is required for tractors without trailers. Fleet terminals also have low labor intensity and maintenance costs (Garber 2015).

We can estimate the minimum occupancy to enable a reasonable payback. It costs $\$ 5,000$ to equip a space with a single-system EPS. If the owner charges $\$ 1.75 / \mathrm{h}$ and incurs costs of only $\$ 0.25$ to operate the unit, net revenue would be $\$ 1.50 / \mathrm{h}$. To pay back the capital cost (without taking into account any interest paid) would require over 3,300 hours of usage. At $10 \%$ occupancy, that is about 4 years; at $20 \%$, it is only 2 years, which is generally an acceptable result. Actual occupancy data show minimal usage in the cool months, requiring very high summer occupancy, such as actually achieved in South Texas, to obtain acceptable payback on the investment. Since the viability of an EPS depends critically on occupancy, we examined actual data from existing locations.

\subsection{OCCUPANCY}

\subsubsection{Single System}

Although several companies have installed single-system EPSs, only one is fully operational as of this writing. IdleAir (Convoy Solutions) purchased the assets of the former company IdleAire, and has taken over other company sites. IdleAir currently has 1,160 gantry spaces at 35 locations, concentrated in the southern United States. Most of these are at truck stops, but several new locations at terminals, including one in Mexico, have recently been opened. The previous company had additional locations, but only the most successful of these were reopened. Between them, CabAire and AireDock account for 11 locations and 335 pedestals, mostly in the eastern United States, and IdleAir has taken them over. IdleAir has graciously provided its detailed operating data (Klat 2015) that show utilization rates for 2014. Those sites reporting showed utilization between $1.3 \%$ and $27.5 \%$, with an average of $10 \%$. The two most successful locations are both in Laredo, Texas. Note that if trucks only park at night, a location that was full every night would only achieve about $50 \%$ utilization. So utilization over $50 \%$ would be unrealistic. 


\subsubsection{Dual System}

Shorepower Technologies is the only supplier of dual-system electrification as of this writing. The Shorepower Truck-Stop Electrification Program (STEP) was funded under the ARRA with the purpose of demonstrating the feasibility of dual-system EPSs. The idea was to solve the chicken-and-egg problem by first covering several major travel corridors with enough locations so that an equipped truck would be assured of places to plug in for the entire route, and second, providing significant equipment cost incentives to trucks that would then utilize the EPS. Almost 1,500 pedestals were installed at more than 60 locations across the country between July 2011 and December 2013. Several corridors were covered, as can be seen on the map in Figure 6. Rebates were provided for more than 4,400 pieces of on-board equipment that could be plugged in. Utilization data for the pedestals were collected, including dates and times of plug-in and disconnect, and power used during the visits.

Results were extremely disappointing. The average utilization across the system was only $0.4 \%$, with only three sites showing utilization over $1 \%$; the highest rate achieved was $7.7 \%$. On average, each pedestal was used under six times for a total of 81.4 hours during the 2-year study period. Average stay duration was 14.3 hours, with an average electricity use of $10.8 \mathrm{kWh}$. There was a mild winter peak of both hours and electricity use (see Figure 20), and usage was highest on weekends (Figure 21). As expected, most bookings were overnight (Figure 22).

Drivers who actually used the service were satisfied. The project final report (Puckette and Kim 2015) offers several possible explanations for the poor usage rates and suggests that installation of at least 200 more facilities would enable much higher usage. Usage data for single-system electrification provide some insights. Low utilization will be discussed after those data are presented.

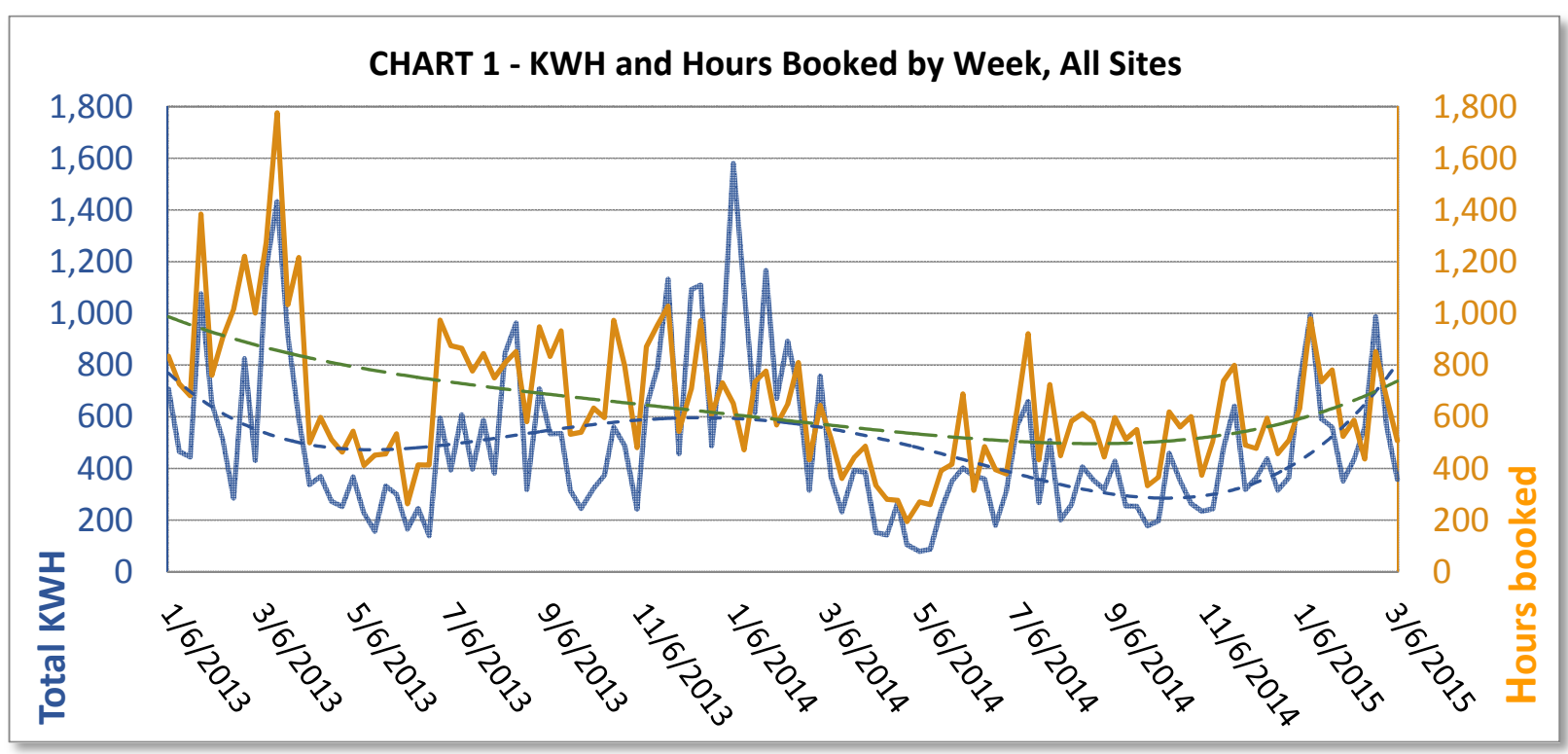

FIGURE 20 Electricity Use for Dual-System EPS (Source: Puckette and Kim 2015) 


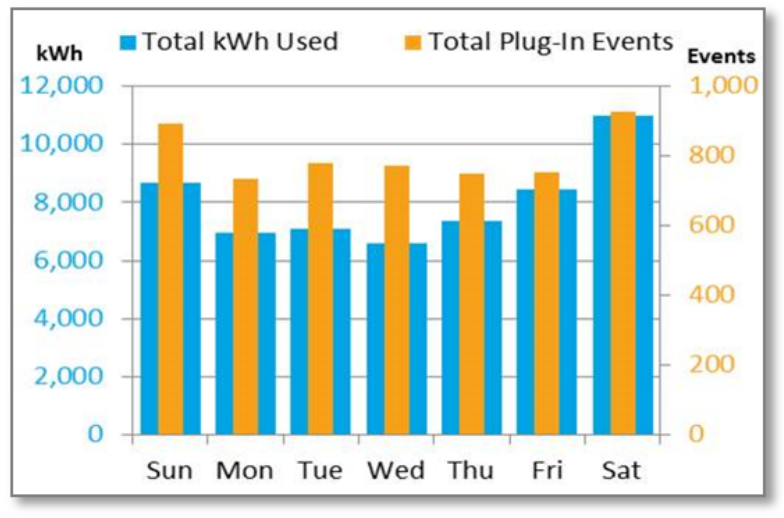

FIGURE 21 Variation of Dual-System Energy Use by Day of the Week (Source: Puckette and Kim 2015)

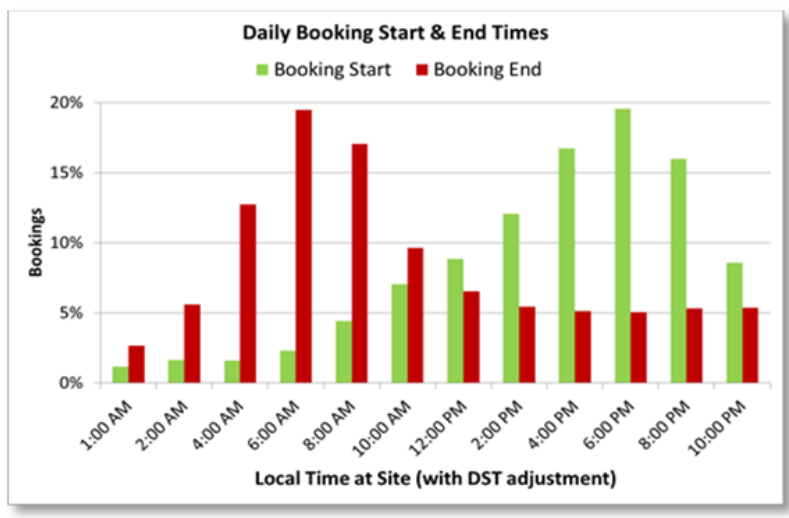

FIGURE 22 Variation of Dual-System EPS Occupancy Energy Use by Time of Day (Source: Puckette and Kim 2015)

\subsection{EPS UTILIZATION}

Although utilization of EPS is generally low, there are some single-system locations that are heavily used. As can be seen in Figure 23, utilization is highest in the South, and singlesystem use peaks in the summer (Figure 24). A major reason for this is reliable air-conditioning that is able to handle the extreme heat load, even over a 34-hour restart. On-board air conditioners may not be able to provide sufficient cooling, and storage air-conditioning may run out, even during a 10-hour stop.

Several dedicated fleet terminals now have EPS installed (see Figure 25). "This is the fastest-growing and most important product," wrote the CEO of IdleAir (Garber 2016). Installation at terminals has several advantages; an ideal situation would have EPS at both ends of a company's route to ensure available service to a captive clientele. Terminals are charged lower hourly rates than truck stops because costs to the equipment owner are lower than at a truck stop; this is one reason why terminals see high usage. Most users opt for basic service because it includes air-conditioning. The power-only option is not used much at terminals, which are in places with mild winter weather. In cooler locations, the power-only option might be more popular, with lower per-hour revenue but possibly higher volume.

The actual current pricing structure for a single-system EPS includes many special incentives to encourage usage. There are also volume discounts for fleets at high usage levels that can reduce all of the prices. Table 2 is a summary of retail services and prices provided by IdleAir. The special offers apply to users staying for periods of 10 hours or more. Note that if they were staying that long routinely, they would be in the high idler category but with a lower average hourly rate than assumed above. This obviously would make EPS more attractive to users. Rates and promotions may vary with time and location; the latest promotions can be found on the company's website (www.idleair.com/promos/). 


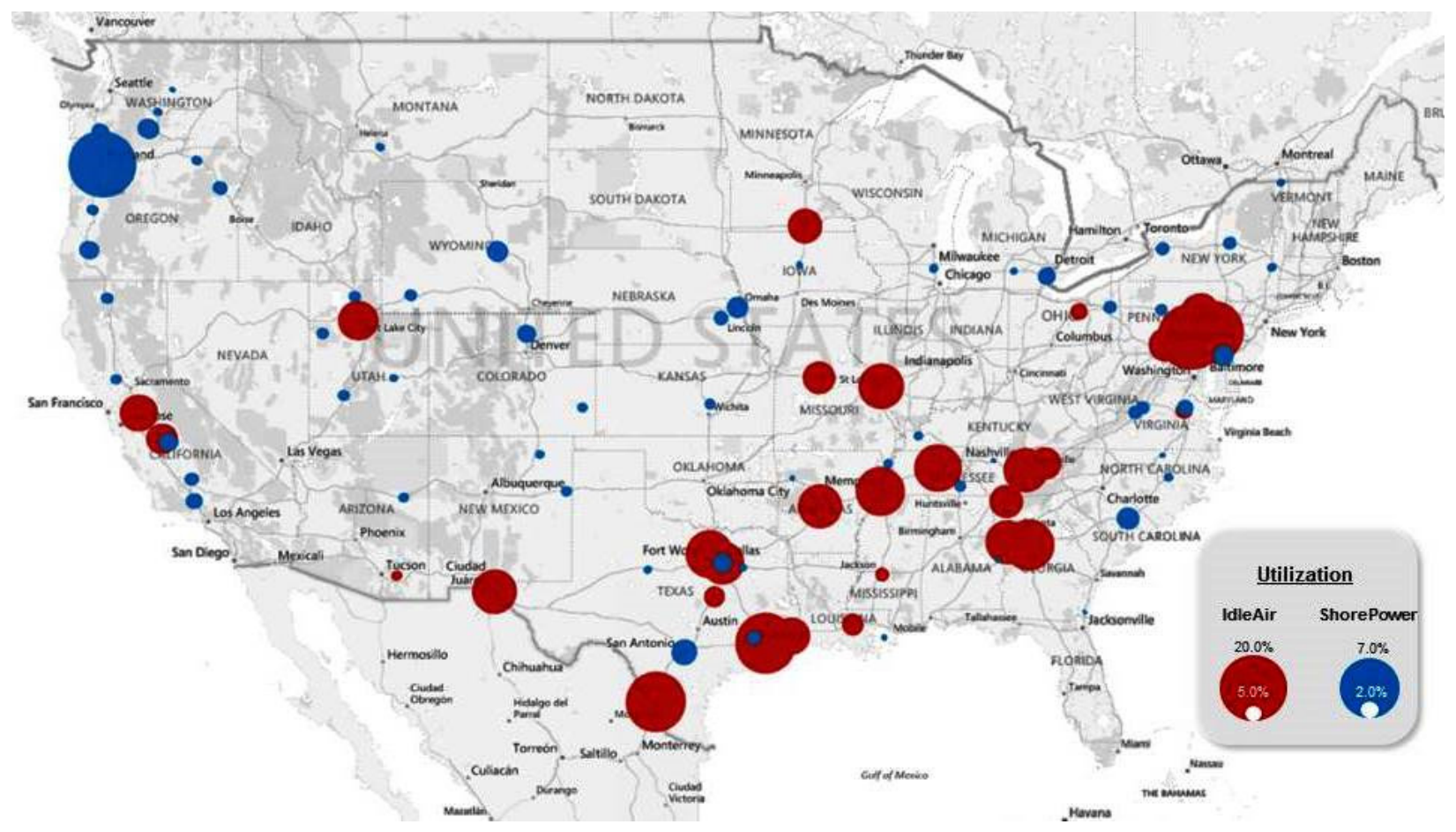

FIGURE 23 Utilization Rates for EPS (red = single system, blue = dual system)

\section{Jan '11 - May '14 Usage: HVAC, Convoy'TV \& Fleet Hours}

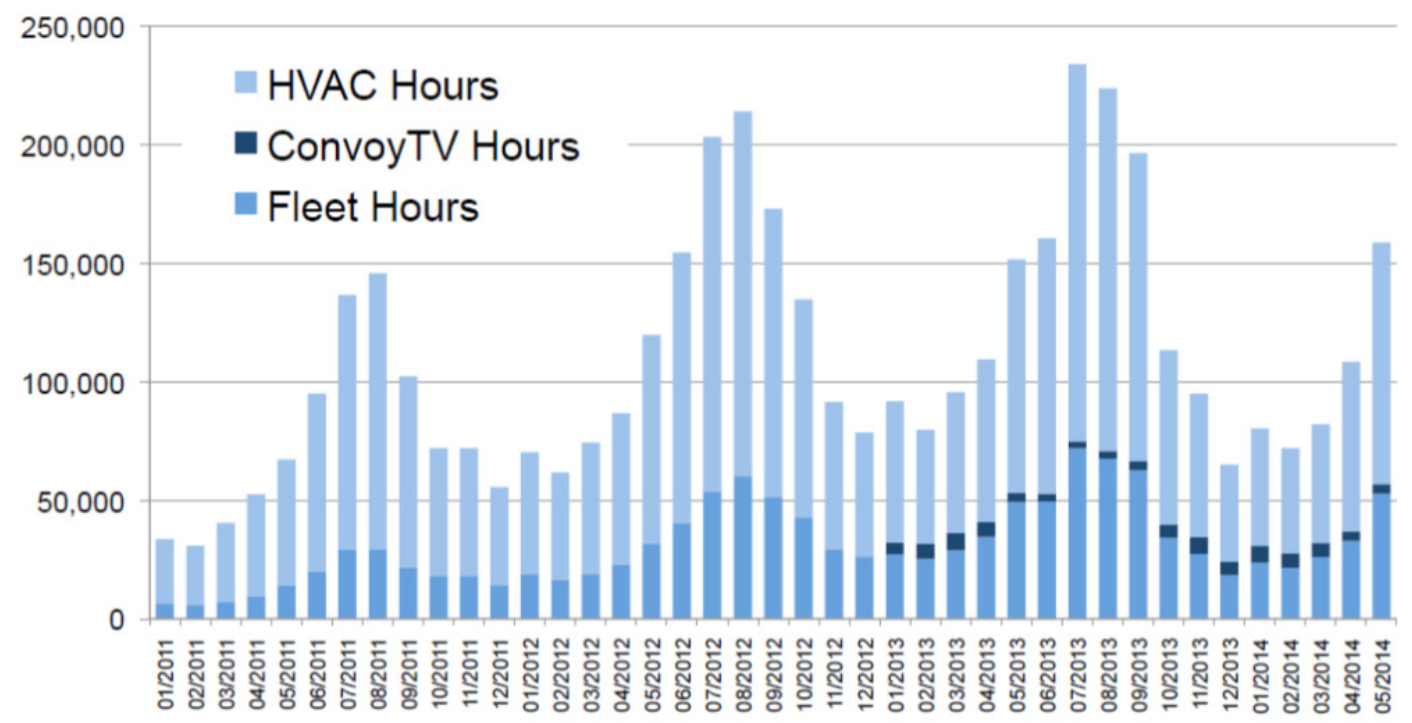

FIGURE 24 Single-System Usage 2011-2014 (Courtesy of IdleAir) 


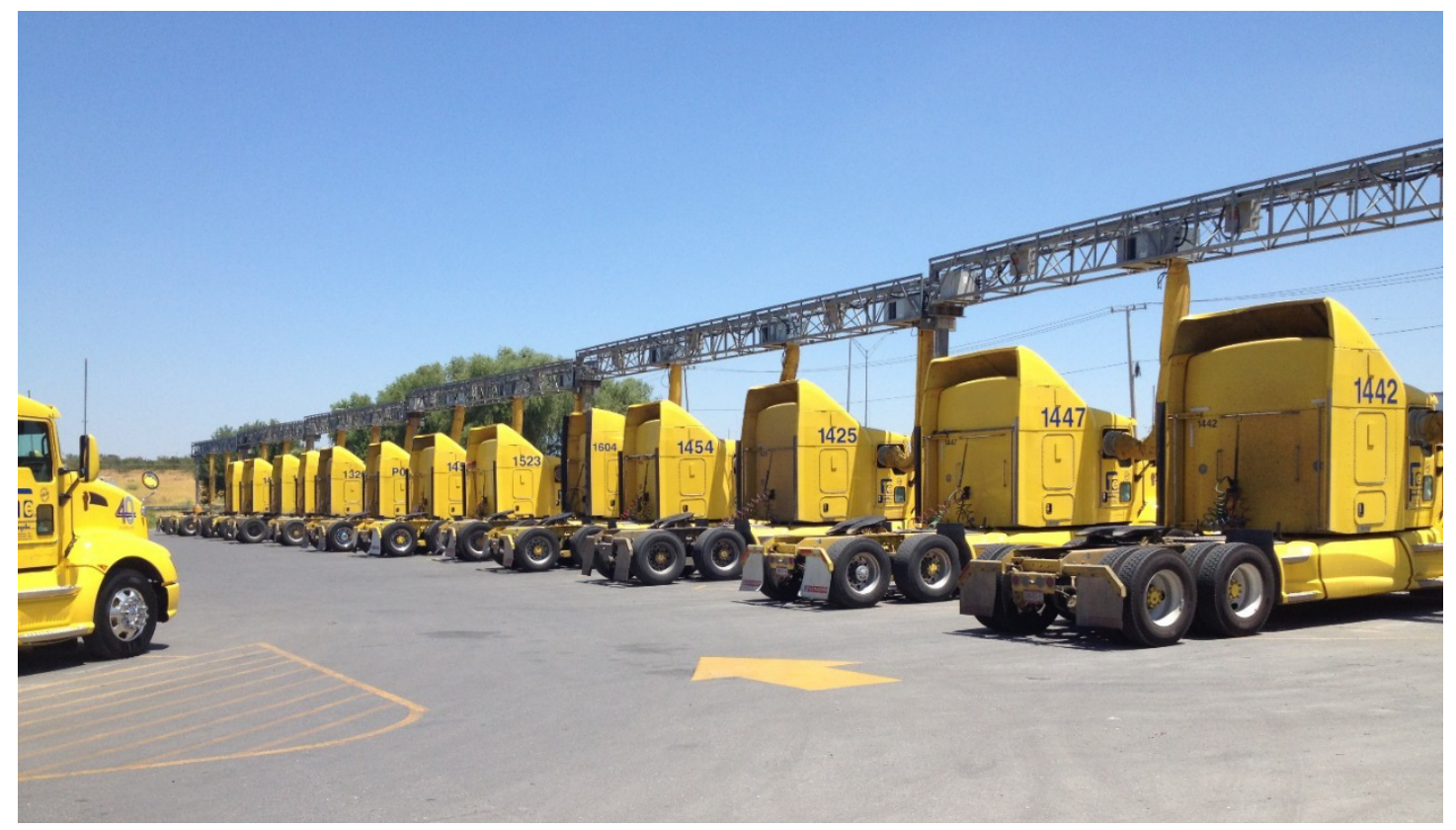

FIGURE 25 IdleAir Facility at Terminal in Mexico (Courtesy of IdleAir)

Many explanations have been given for low utilization at locations without a high need for air-conditioning:

- There are not enough locations, and some are not convenient or are not well equipped with amenities truckers need, like showers.

- At many locations, there is not sufficient parking, and the EPS spots are often blocked by other trucks that are not plugged in but can find no place else to park.

- Many truckers do not know about the service, and truck stop management does not necessarily promote it effectively.

- The signage is sometimes inadequate.

- Some truck drivers might use the service if their companies reimbursed them or if they could use their fuel cards to pay.

- Many fleets are uninterested in using EPS, and, at low fuel prices, the service is less attractive financially.

These explanations may or may not fully explain the low usage. The STEP final report (Puckette and Kim 2015) suggests that careful siting of at least 200 more locations would be necessary to achieve sufficient momentum for EPS. 
This page left intentionally blank. 


\section{CONCLUSIONS}

This report compares the relative economics of different IR devices as a function of hours the equipment is utilized and the price of diesel fuel. All IR options are cheaper to operate than idling when the price of fuel is more than $\$ 2 /$ gal, and so all provide good insurance against high fuel prices. In addition, all reduce emissions, are quieter, produce less vibration than idling, and enable compliance with local anti-idling regulations. ${ }^{6}$ The high capital cost of some on-board options requires many hours of use to pay back. An APU may be able to achieve additional years of service if supplemented by a heater. In summary, for low idlers who have the option, plugging in has the lowest total cost. Low fuel cost favors on-board options for high idlers, and the addition of a heater helps make APU competitive at high fuel cost.

But there is no one-size-fits-all technology for reducing idling, and, in the real world, other factors come into play in addition to minimizing total costs. The most important factor is driver comfort, and seasonal and locational factors impact choices for cab comfort. The truck owner can save money if the driver does not need all services, so on northern routes, the driver may be able to stay warm and comfortable overnight with just a fuel-fired heater, using the truck's battery (and maybe an extra) for lights, microwave, refrigerator, etc. In the far South, air-conditioning is the key service, as shown by high summer use of EPS in Texas. Usage is heavy there, even though it is not available everywhere on the truckers' routes, because on-board air-conditioning may not always be able to keep up with the high summer heat load.

Another factor impacting technology choice is the restart rule, which requires drivers to have a 34-hour rest stop after 60 or 70 hours of driving. Equipment that is powered by stored energy - either a battery or thermal storage — does not have sufficient capacity to power the sleeper for the entire time period. Therefore, if there is no place to plug in, the truck must be idled to recharge the system, which may be illegal.

In summary, there is no one-size-fits-all option, but a wide variety of IR options that enable truck drivers to stay comfortable, comply with regulations, and keep costs down.

6 This may not be a major incentive in most places, as enforcement of idling regulations is often lacking. 
This page left intentionally blank. 


\section{REFERENCES}

ATRI (American Transportation Research Institute), 2006, Idle Reduction Technology: Fleet Preferences Survey, prepared by ATRI, Alexandria, Va., for New York State Energy Research and Development Authority, February. Available at http://www.atri-online.org/research/results/ IdleReductionTechnologyFleetPreferencesSurvey.pdf.

ATRI, 2016, "Compendium of Idling Regulations." Available at http://atri-online.org/wpcontent/uploads/2016/06/2016-ATRI-IdlingCompendium-06-2016.pdf. Accessed Aug. 9, 2016.

Boyer, D., 2006, personal communication from Boyer (Autotherm) to L. Gaines (Argonne National Laboratory, Argonne, Ill.), June.

CARB (California Air Resources Board), 2013, "Facts about California's Commercial Vehicle Idling Regulations.” Available at http://www.arb.ca.gov/msprog/truck-idling/factsheet.pdf.

EIA (Energy Information Administration), 2016, Annual Energy Outlook 2016. Available at http://www.eia.gov/forecasts/aeo/section_prices.cfm\#petliquids.

EPA (U.S. Environmental Protection Agency), 2016, "Verified Technologies for SmartWay and Clean Diesel.” Available at https://www.epa.gov/verified-diesel-tech.

FMCSA (Federal Motor Carrier Safety Administration), 2014, "Summary of Hours of Service Regulations." Available at http://www.fmcsa.dot.gov/regulations/hours-service/summary-hoursservice-regulations. Accessed Aug. 10, 2016. Enforcement of part of the rule has been suspended, and discussion continues.

Gaines, L., and C-J. Brodrick Hartman, 2009, "Energy Use and Emissions Comparison of Idling Reduction Options for Heavy-Duty Diesel Trucks," in Proceedings of the Transportation Research Board Annual Meeting, January.

Gaines, L., and A. Burnham, 2016, "Emissions from Idling Heavy-Duty Trucks and Idling-Reduction Equipment, " in Proceedings of the Transportation Research Board Annual Meeting, January.

Gaines, L., Vyas, A., and J.L. Anderson, 2006, "Estimation of Fuel Use by Idling Commercial Trucks," TRB Paper 06-2567, Journal of the Transportation Research Board 1983(1):91-98.

Garber, E., 2015, personal communication from Garber (Convoy Solutions, Knoxville, Tenn.) to L. Gaines (Argonne National Laboratory, Argonne, Ill.), Feb. 20.

Garber, E., 2016, personal communication from Garber (Convoy Solutions, Knoxville, Tenn.) to L. Gaines (Argonne National Laboratory, Argonne, Ill.), March 16. 
Gibbs, J., 2016, personal communication from Gibbs (U.S. Department of Energy, Office of Energy Efficiency \& Renewable Energy) to L. Gaines (Argonne National Laboratory, Argonne, I11.) Aug. 17.

Klat, Y., 2015, personal communication from Klat (Convoy Solutions, Knoxville, Tenn.) to L. Gaines (Argonne National Laboratory, Argonne, Ill.), Oct. 23.

Ladage, A., 2006, “FHWA officials say APU weight exemption not mandatory," Today's Trucking News. Available at http://www.landlinemag.com/todays_news/Daily/2006/ May06/051706.htm. Accessed May 18, 2006.

NACFE (North American Council for Freight Efficiency), 2014a, 2014 Fleet Fuel Efficiency Benchmark Study, August 31. Available at http://nacfe.org/wp-content/uploads/ 2014/09/NACFE-2014-Study-Report-FINAL-083114.pdf.

NACFE, 2014b, Confidence Report: Idle-Reduction Solutions, Trucking Efficiency. Available at http://carbonwarroom.com/sites/default/files/reports/Idle-Reduction_Confidence_Report.pdf.

NACFE, 2016, 2016 Annual Fleet Fuel Study, August 24. Available at http://www.truckingefficiency.org/annual-fleet-fuel-studies.

Puckette, M., and J. Kim, 2015, Interstate Electrification Improvement Project Final Report, prepared by Shorepower Technologies for U.S. Department of Energy National Energy Technology Laboratory, July. Available at http://www.osti.gov/scitech/servlets/purl/1234444. Accessed Aug. 10, 2016.

USCB (U.S. Bureau of the Census), 2002, Vehicle Inventory and Use Survey - Discontinued, 2002 Data Releases. Available at https:/www.census.gov/svsd/www/vius/2002.html. 


\section{APPENDIX}

\section{WORKSHEET FOR CALCULATING PAYBACK}

The worksheet in this Appendix can be used to estimate savings and payback for the truck owner. It is filled out for an example auxiliary power unit (APU) and is also available as an Excel spreadsheet (http://www.anl.gov/energy-systems/downloads/vehicle-idle-reductionsavings-worksheet). Repeated use of the worksheet allows comparison among devices. The simple worksheet does not take loans and leases into account. Several other calculators are available. Some simply calculate the cost of fuel that would have been burned during idling. Others compute monthly savings if the truck owner purchases a device using a loan. Most calculators do not include maintenance and overhaul costs and savings, or estimate savings from using wayside systems (Bergstrom undated; Proheat undated).

The economic benefits of idle reduction (IR) technologies depend on the costs avoided by not idling, and on the costs incurred to purchase or lease and use the IR technology. Fuel and maintenance costs for idling are added to determine the total annual cost for idling the truck. For most cases, the fuel cost dominates, representing as much as $95 \%$ of the total. Thus just calculating fuel cost is a good first approximation to the cost of idling. The operating costs for the IR alternative are then calculated by adding up its fuel and maintenance costs. If a plug-in device is used, the cost for plugging it in is added to the cost of IR. The operating cost for the IR device is then subtracted from that for idling to determine the annual savings in operating cost resulting from use of the IR device. Finally, the payback time (in years) for the IR technology is calculated by dividing the device cost by the annual savings.

This appendix walks the user through the process of filling out a worksheet. The user must supply several inputs to the cost calculations. Actual idling and device data can be entered if available; if not, the default values shown in Table 1 of the main report can be used to obtain approximate answers.

Line 1: Line 1 calculates idling fuel use. The user is first asked about per-hour idling fuel use, which may not be well known. Therefore, a table is provided at the bottom of the worksheet to enable the user to estimate idling fuel as a function of load. We have entered 0.8 gallons per hour, corresponding to a truck idled at about 900 RPM, with the air on half of the time. The next number required is the number of idling hours per year that an alternative to idling could be used. It includes only time parked, not time when the truck must idle in traffic. This is a key number for any IR technology evaluation. The more idling hours avoided, the more rapidly any device pays back its investment. Several studies have attempted to determine average truck idling times. Based on discussions with the American Trucking Associations, we estimated typical overnight idling at 1,830 hours per year in 2000 (Stodolsky et al. 2000). The U.S. Environmental Protection Agency (EPA) and equipment manufacturer materials estimated 2,400 hours or more. Surveys conducted by the University of California at Davis showed that there is actually a huge 


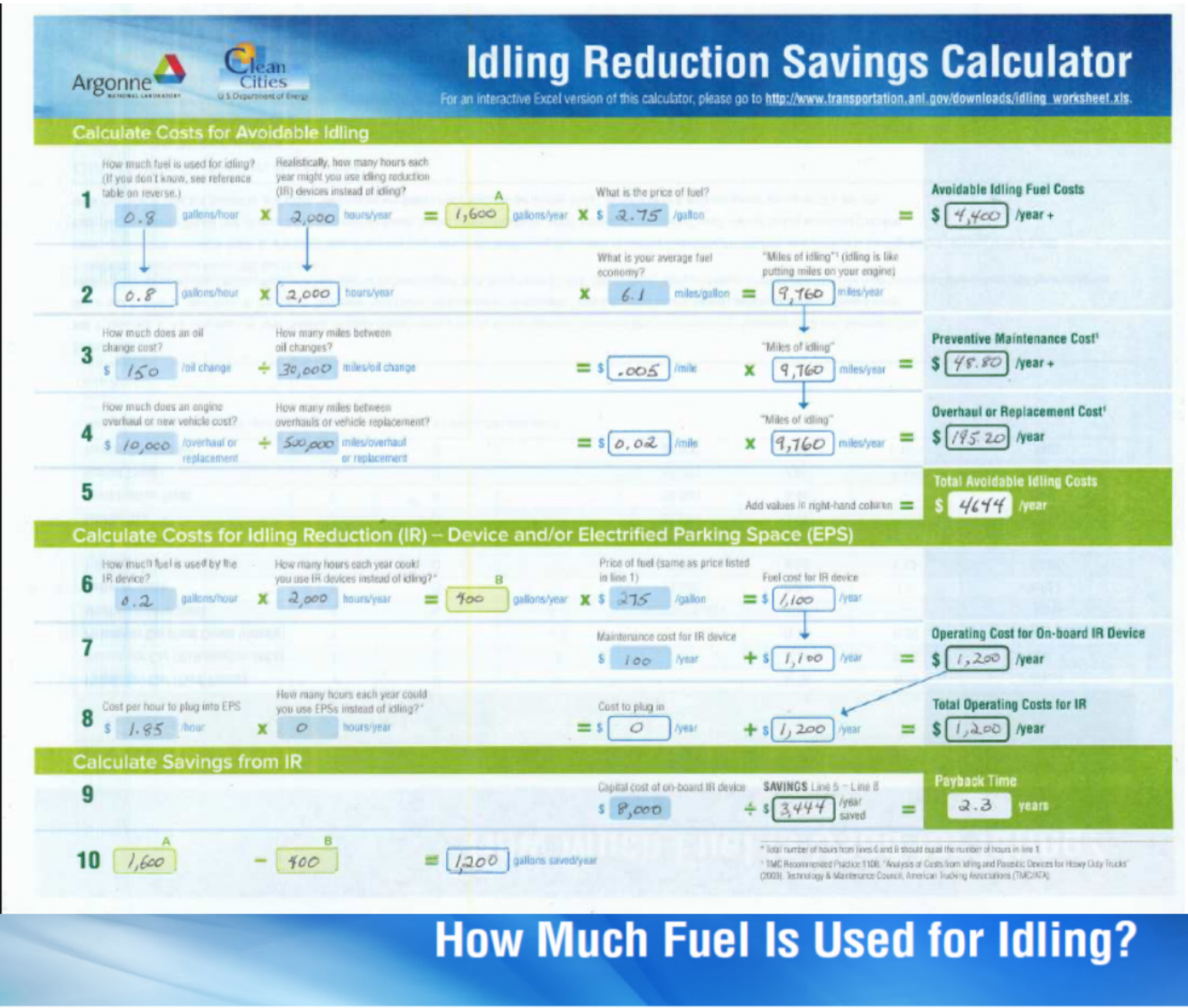

\begin{tabular}{|c|c|c|c|c|c|c|c|}
\hline \multirow[b]{2}{*}{ Vehicle Type } & \multirow[b]{2}{*}{ Class } & \multirow[b]{2}{*}{ Fuel Type } & \multicolumn{2}{|c|}{ Size Indicator } & \multicolumn{2}{|c|}{ Idling Fuel Use (gal/h) } & \multirow[b]{2}{*}{ Source } \\
\hline & & & $\begin{array}{c}\text { Engine Size } \\
\text { (I) }\end{array}$ & $\begin{array}{c}\text { GVWR } \\
\text { (lb) }\end{array}$ & No load & With load & \\
\hline Passenger Car (Ford Focus) & 1 & G & 2 & - & 0.16 & 0.29 & ANL 1 \\
\hline Passenger Car (Volkswagen Jetta) & 1 & D & 2 & - & 0.17 & 0.39 & ANL 1 \\
\hline Passenger Car (Ford Crown Victoria) & 1 & G & 4.6 & - & 0.39 & 0.59 & ANL $1 \& 2$ \\
\hline Medium Heavy Truck & 6 & G & 5-7 & $19,700-26,000$ & 0.84 & - & WVU \\
\hline Delivery Truck & 5 & D & - & 19,500 & 0.84 & $1.1^{1}$ & NREL \\
\hline Tow Truck & 6 & D & - & 26,000 & 0.59 & $1.14^{2}$ & ORNL \\
\hline Medium Heavy Truck & $6-7$ & D & $6-10$ & $23,000-33,000$ & 0.44 & - & WVU \\
\hline Transit Bus & 7 & D & - & 30,000 & 0.97 & - & ORNL \\
\hline Combination Truck & 7 & D & - & 32,000 & 0.49 & - & ORNL \\
\hline Bucket Truck & 8 & D & - & 37,000 & 0.90 & $1.50^{2}$ & ORNL \\
\hline Tractor-Semitrailer & 8 & D & - & 80,000 & 0.64 & $1.15^{311}$ & TMC \\
\hline \multicolumn{8}{|c|}{ 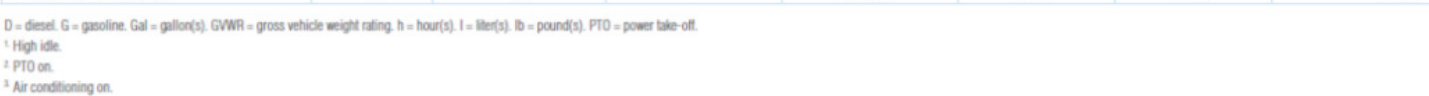 } \\
\hline
\end{tabular}

\section{Sources}

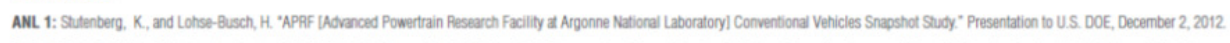

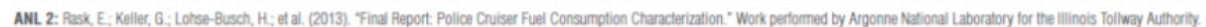

NREL: National Renewable Energy Laboratory Project Dratt Final Report tor the Period August 1, 2012, through March 31, 2014, "Data Collection, Testing and Analysis of Hybrid Electric Trucks and Buses Operating in California Fleets" ARB Agreernent Number 11-600, NAEL Contract Number FlA-12-1763, April 15, 2014

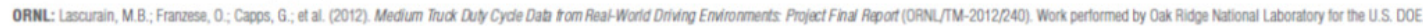

TMC: TMC Recommended Practice 1108, "Analysis of Costs trom Idling and Parasitic Devices tor Heawy Duty Trucks" (2003). Technology \& Maintenance Council, American Trucking Associations (TMC/ATA).

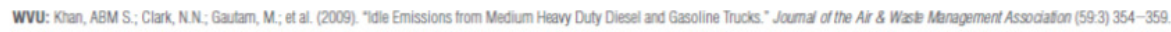


range of practice, with drivers idling overnight anywhere from 500 to more than 3,000 hours per year. No estimates of workday idling were published until 2006, when we estimated a range of 150 to 900 hours annually for all commercial trucks, depending on the type of service (Gaines et al. 2006). A survey (including fleets totaling 55,000 trucks) by the American Transportation Research Institute (ATRI 2006) indicates an average of 1,456 hours per year for sleeper cabs and 312 hours per year for day cabs, presumably only heavy trucks. If the truck idles overnight for 10 hours, 4 nights per week, 50 weeks per year, the IR device could be used for 2,000 hours, which is entered into the example sheet.

The next entry is the average price of diesel fuel the user expects to pay during the lifetime of the equipment. Because this is so uncertain, we look at a range of fuel prices in the sensitivity analysis section. For this example, $\$ 2.75$ per gallon is used. These first three worksheet entries are then multiplied together to give the total fuel cost for idling, which is $\$ 4,400$ per year in this example.

Line 2: The first two numbers in this line are simply copied down from Line 1 . The next entry is the truck's average fuel economy, which is used to estimate the equivalent number of miles for estimating maintenance and overhaul costs caused by idling. We have entered $6.1 \mathrm{mpg}$, the average fuel economy of new long-haul trucks in the 2002 Vehicle Inventory and Use Survey (USBC 2004). Multiplying these three numbers together gives a total "miles of idling" of 9,760 miles per year for the example. The Technology and Maintenance Council (TMC) of the American Trucking Associations published two Recommended Practice (RP) Bulletins to help truckers estimate idling costs. The first, published in 1985, was superseded by another in 1995 (TMC 1995), in which the cost estimates were drastically reduced due to the reduction in fuel sulfur and changes in idling practice. We used the updated version. The main difference is the number of "equivalent miles" represented by idling. The revised RP estimates this from the fuel consumption; that is, they assume that each gallon of fuel burned is associated with the same amount of engine wear. Thus, each gallon of fuel used idling is accounted for as if it achieved the truck's average miles per gallon, and the number of equivalent miles is calculated. For a Class 8 truck, 1 hour of idling is typically equivalent to about 6 miles of driving.

Line 3: This line asks for cost of an oil change and number of miles between changes. In addition to savings from reduced fuel consumption, not idling a truck reduces maintenance costs. Oil changes can be performed less frequently if the engine is operated for fewer hours; thus the cost for oil changes can be reduced. We have entered values of $\$ 150$ for an oil change every 30,000 miles. The cost is divided by the number of miles to give a per-mile cost, in this case a half a cent per mile. This gets multiplied by the annual "miles of idling," brought down from Line 2, to give an annual oil change cost of $\$ 48.80$ due to idling.

Line 4: Idling wears the engine and contributes to the truck needing an overhaul sooner than if it did not idle. Some trucks just need part replacements, costing about $\$ 2,500$, while others might need a full engine-out overhaul, costing as much as $\$ 20,000$. There is also considerable variation in mileage to overhaul; a typical mileage used to be 300,000 , but now may be up to 1,000,000 miles, and no overhaul may ever be performed (Laible 2004). The worksheet allows the user to select appropriate entries for these parameters, or to omit this term. Many truck 
owners sell their trucks before overhaul, and therefore may choose to omit this component. However, if the buyer can see the truck's idling history in its computer records, the purchase price will theoretically be reduced for a truck that has idled excessively.

The cost of an overhaul (here taken to be $\$ 10,000$ ) and the expected mileage $(500,000$ miles for the example) are entered and divided to give a per-mile cost, in this case 2 cents. This is multiplied by the number of miles to give a prorated annual cost due to requiring an overhaul sooner for a truck that idles. For the example, this is $\$ 195.20$, much smaller than the fuel cost.

Line 5: The three costs in the right-hand column (fuel cost in Line $1=\$ 4,400$; preventive maintenance in Line $3=\$ 48.80$; and overhaul cost in Line $4=\$ 195.20$ ) are added up to calculate the total cost that could be avoided by using an IR device instead of idling. In the example, that total is $\$ 4,644$ per year.

Of course that is only part of the story, because IR is not free. The user needs to estimate the costs of IR and subtract them from the gross savings to obtain the net savings.

Line 6: Line 6 calculates the fuel cost for an on-board IR device. The fuel use per hour for the IR device is entered in the first box. If this is not available from the manufacturer or owner experience, a default value from Table 1 of the main text can be used. The defaults include our estimates of fuel required during on-road operation to charge energy storage devices such as batteries or thermal storage. [Note: fuel use can vary by season and location; use an average in the worksheet.] For an electrified parking space (EPS) system, this term is zero because the cost of the electricity is generally included in the hourly charge. For the example, we used a typical APU fuel consumption of 0.2 gallons per hour. The number of hours and diesel price should be brought down from Line 1. In the example, IR fuel cost is $\$ 1,100$ per year.

Line 7: Line 7 asks for the maintenance cost for the on-board IR device, which we have estimated as $\$ 100$ for an APU. The device supplier can provide an estimate for the model you are considering. This cost is added to the IR fuel cost, brought down from Line 6, to give the operating cost for the on-board IR device, in the example, $\$ 1,200$ per year.

Line 8: Line 8 calculates the cost for plugging into EPSs. The hourly cost is entered and multiplied by the number of hours the truck is expected to plug in per year to give a total annual plug-in cost. The number of hours will likely be smaller than the number of hours an on-board device could be used because of lack of facility availability. In our example, the user is not expected to plug in at all because a stand-alone on-board device is being evaluated. Any plug-in charges are added to the on-board device operating costs to give a total operating cost for the IR device, which is $\$ 1,200$.

Line 9: This is the bottom line! The user is asked for one final input: the installed capital cost of the on-board equipment, in our example, $\$ 8,000$. If the device is to be part of the original equipment, Federal Excise Tax will need to be included (aftermarket devices are exempt). (This is a disincentive for original equipment manufacturer [OEM] installation.) The installation cost for a retrofit should include the cost of any additional downtime if the unit is to be installed other 
than during a standard maintenance period. If the user is evaluating single-system wayside service, the capital cost to the truck owner is $\$ 5$. If there is a grant or rebate expected to help fund the purchase of equipment to be used with dual-system EPS, this amount should be subtracted from the up-front capital cost. A tax credit could be accounted for in the same way.

The IR operating cost in Line 8 ( $\$ 1,200$ in the example) is subtracted from the idling cost in Line 5 ( $\$ 4,644$ in the example) to give annual savings from use of the IR device $(\$ 3,444$ in the example). Finally, the capital cost is divided by the savings to give a simple payback period, 2.3 years in the example.

Line 10: Line 10 has been added to tell the user what reductions in petroleum use can be expected. 


\section{REFERENCES}

ATRI (American Transportation Research Institute), 2006, Idle Reduction Technology: Fleet Preferences Survey, prepared by ATRI, Alexandria, Va., for New York State Energy Research and Development Authority, February. Available at http://www.atri-online.org/research/results/ Idle\%20Reduction\%20Technology\%20Fleet\%20Preferences\%20Survey.pdf. Accessed May 26, 2006.

Bergstrom, undated, “Calculate savings.” Available at http://us.bergstrominc.com/nite-calculatesavings/. Accessed Aug. 9, 2016.

Gaines, L., A. Vyas, and J.L. Anderson, 2006, "Estimation of Fuel Use by Idling Commercial Trucks," TRB Paper 06-2567, Journal of the Transportation Research Board 1983(1):91-98.

Laible, A., 2004, personal communication from Laible (Cox Transfer, Eureka, Ill.) to L. Gaines (Argonne National Laboratory, Argonne, Ill.), January.

Proheat, undated, "US Idle Cost Calculator (Canadian Version).” Available at http://proheat.com/support/idleCostUS.php. Accessed Aug. 9, 2016.

Stodolsky, F., L. Gaines, and A. Vyas, 2000, Analysis of Technology Options to Reduce Fuel Consumption of Idling Trucks, ANL/ESD-43, Argonne National Laboratory, Argonne, Ill., June.

TMC (Technology and Maintenance Council), 1995, "Analysis of Costs from Idling and Parasitic Devices for Heavy Duty Trucks” Recommended Practice Bulletin 1108, March (reprinted 2003 by TMC/American Trucking Associations).

USBC (U.S. Bureau of the Census), 2004, Vehicle Inventory and Use Survey: 2002 - Microdata File, U.S. Department of Commerce, Washington, D.C. 



\section{Argonne}

\section{Energy Systems Division}

9700 South Cass Avenue, Bldg. 362

Argonne, IL 60439-4854

www.anl.gov 